UNIVERSIDAdE DE SÃo PAULO

Faculdade de EConomia, Administração e Contabilidade de Ribeirão Preto DePartamento de ECONOMia

Programa de Pós-GraduaÇão em Economia - Área: Economia APlicada

GILBERTO OLIVEIRA BOARETTO

Estimação de modelos DSGE usando verossimilhança empírica e mínimo contraste generalizados

Orientador: Prof. Dr. Márcio Poletti Laurini

Ribeirão Preto

2018 
Prof. Dr. Marco Antonio Zago

Reitor da Universidade de São Paulo

Prof. Dr. Dante Pinheiro Martinelli

Diretor da Faculdade de Economia, Administração e Contabilidade de Ribeirão Preto

Prof. Dr. Renato Leite Marcondes

Chefe do Departamento de Economia

Prof. Dr. Sergio Naruhiko Sakurai

Coordenador do Programa de Pós-Graduação em Economia 
GILBERTO OLIVEIRA BOARETTO

\title{
Estimação de modelos DSGE usando verossimilhança empírica e mínimo contraste generalizados
}

\author{
Dissertação de mestrado apresentada ao Pro- \\ grama de Pós-Graduação em Economia - Área: \\ Economia Aplicada da Faculdade de Econo- \\ mia, Administração e Contabilidade de Ribeirão \\ Preto da Universidade de São Paulo para obten- \\ ção do título de Mestre em Ciências. Versão \\ Corrigida. A original encontra-se disponível na \\ FEA-RP/USP.
}

Orientador: Prof. Dr. Márcio Poletti Laurini

Ribeirão Preto 
Autorizo a reprodução e divulgação total ou parcial deste trabalho, por qualquer meio convencional ou eletrônico, para fins de estudo e pesquisa, desde que citada a fonte.

BOARETTO, Gilberto Oliveira.

Estimação de modelos DSGE usando verossimilhança empírica e mínimo contraste generalizados / Gilberto Oliveira Boaretto Ribeirão Preto, SP, 2018.

61 p.: il.; $30 \mathrm{~cm}$

Dissertação de mestrado apresentada ao Programa de PósGraduação em Economia - Área: Economia Aplicada da Faculdade de Economia, Administração e Contabilidade de Ribeirão Preto da Universidade de São Paulo, para obtenção do título de Mestre em Ciências. - Universidade de São Paulo

Orientador: Laurini, Márcio Poletti

1. Modelos de Equilíbrio Geral Dinâmico e Estocástico.

2. Verossimilhança Empírica. 3. Mínimo Contraste. 
Para minha mãe Lucia, meus avós Onofra Luiza e João Borges (in memoriam) e minha avó Maria Ilda. 



\section{Agradecimentos}

À minha mãe Lucia por todo o apoio importantíssimo para a finalização de mais esta etapa da minha vida.

À minha avó Onofra que infelizmente faleceu ao longo do mestrado, mas que sempre me incentivou e almejou que eu continuasse avançando.

Ao Marcos por toda a ajuda durante a ida e a saída de Ribeirão Preto e por sempre estar ao lado da minha mãe.

Ao meu pai Ventomar, à minha avó Maria Ilda e aos meus padrinhos Elzeli e Geraldo.

Ao meu orientador Márcio Laurini com quem tive a oportunidade de aprender bastante ao longo deste mestrado e que sempre terei como exemplo de pesquisador.

Aos professores Fábio Gomes e Jefferson Bertolai pelas sugestões durante as etapas de qualificação e pré-defesa que contribuíram bastante para a obtenção desta versão do trabalho.

Aos professores Andreza Palma, Diogo de Prince e Fábio Gomes por terem aceitado o convite para participar da minha banca e por todas as valiosas sugestões dadas.

A todos os professores do PPGE/FEARP/USP com os quais tive contato seja em sala de aula seja em atividade acadêmica de outra natureza.

A todos os técnicos e funcionários da FEARP/USP.

Ao amigo Henrique, aos alunos de graduação e aos professores Rudinei, Luciano e Sakurai com os quais tive a oportunidade de trabalhar no Centro de Pesquisa em Economia Regional da FUNDACE (CEPER).

Ao meu professor e orientador de graduação Cleomar que continuou me dando dicas e ajudando. Aos meus amigos Régis, Japa (Marcos) e Chaim com os quais tive a satisfação de dividir moradia em Ribeirão Preto ao longo destes dois anos. Além da amizade e companheirismo, eles incentivaram bastante a discussão dos mais variados temas, o que contribuiu enormemente para o meu amadurecimento pessoal e acadêmico.

A todos os amigos do PPGE/FEARP/USP com os quais convivi boa parte do tempo nestes dois anos de mestrado e com os quais bebi bastante café para manter o ritmo de estudos e bastante cerveja para descontrair um pouco. Satisfação enorme ter vivido esta fase da vida com vocês!

A todos os amigos que fiz em Ribeirão Preto, em especial à Luara que tive o prazer de conhecer no segundo ano do mestrado e que me apoiou bastante na decisão de fazer doutorado.

À CAPES e à FUNDADE pelo apoio financeiro concedido ao longo do mestrado.

Ao Estado brasileiro e a todos os seus mantenedores. 



\section{Resumo}

\section{BOARETTO, G. O. Estimação de modelos DSGE usando verossimilhança empírica e mí-}

nimo contraste generalizados. Dissertação (Mestrado) - Faculdade de Economia, Administração e Contabilidade de Ribeirão Preto, Universidade de São Paulo, Ribeirão Preto, 2017.

O objetivo deste trabalho é investigar o desempenho de estimadores baseados em momentos das famílias verossimilhança empírica generalizada (GEL) e mínimo contraste generalizado (GMC) na estimação de modelos de equilíbrio geral dinâmico e estocástico (DSGE), com enfoque na análise de robustez sob má-especificação, recorrente neste tipo de modelo. Como benchmark utilizamos método do momentos generalizado (GMM), máxima verossimilhança (ML) e inferência bayesiana (BI). Trabalhamos com um modelo de ciclos reais de negócios (RBC) que pode ser considerado o núcleo de modelos DSGE, apresenta dificuldades similares e facilita a análise dos resultados devido ao menor número de parâmetros. Verificamos por meio de experimentos de Monte Carlo se os estimadores estudados entregam resultados satisfatórios em termos de média, mediana, viés, erro quadrático médio, erro absoluto médio e verificamos a distribuição das estimativas geradas por cada estimador. Dentre os principais resultados estão: $(i)$ o estimador verossimilhança empírica (EL) - assim como sua versão com condições de momento suavizadas (SEL) - e a inferência bayesiana (BI) foram, nesta ordem, os que obtiveram os melhores desempenhos, inclusive nos casos de especificação incorreta; (ii) os estimadores continous updating empirical likelihood (CUE), mínima distância de Hellinger (HD), exponential tilting (ET) e suas versões suavizadas apresentaram desempenho comparativo intermediário; (iii) o desempenho dos estimadores exponentially tilted empirical likelihood (ETEL), exponential tilting Hellinger distance (ETHD) e suas versões suavizadas foi bastante comprometido pela ocorrência de estimativas atípicas; ( $i v)$ as versões com e sem suavização das condições de momento dos estimadores das famílias GEL/GMC apresentaram desempenhos muito similares; (v) os estimadores GMM, principalmente no caso sobreidentificado, e ML apresentaram desempenhos consideravelmente abaixo de boa parte de seus concorrentes.

Palavras-chave: modelos de equilíbrio geral dinâmico e estocástico, método dos momentos, verossimilhança empírica, mínimo contraste, mínima distância de Hellinger. 



\section{Abstract}

BOARETTO, G. O. DSGE Estimation using Generalized Empirical Likelihood and Generalized Minimum Contrast. Dissertation (Master Degree) - School of Economics, Business and Accounting at Ribeirão Preto, University of São Paulo, Ribeirão Preto, 2017.

The objective of this work is to investigate the performance of moment-based estimators of the generalized empirical likelihood (GEL) and generalized minimum contrast (GMC) families in the estimation of dynamic stochastic general equilibrium (DSGE) models, focusing on the robustness analysis under misspecification, recurrent in this model. As benchmark we used generalized method of moments (GMM), maximum likelihood (ML) and Bayesian inference (BI). We work with a real business cycle (RBC) model that can be considered the core of DSGE models, presents similar difficulties and facilitates the analysis of results due to lower number of parameters. We verified, via Monte Carlo experiments, whether the studied estimators presented satisfactory results in terms of mean, median, bias, mean square error, mean absolute error and we verified the distribution of the estimates generated by each estimator. Among the main results are: $(i)$ empirical likelihood (EL) estimator - as well as its version with smoothed moment conditions (SEL) - and Bayesian inference (BI) were, in that order, the ones that obtained the best performances, even in misspecification cases; (ii) continuous updating empirical likelihood (CUE), minimum Hellinger distance (HD), exponential tilting (ET) estimators and their smoothed versions exhibit intermediate comparative performance; (iii) performance of exponentially tilted empirical likelihood (ETEL), exponential tilting Hellinger distance (ETHD) and its smoothed versions was seriously compromised by atypical estimates; (iv) smoothed and non-smoothed GEL/GMC estimators exhibit very similar performances; ( $v$ ) GMM, especially in the over-identified case, and ML estimators had lower performance than their competitors.

Keywords: dynamic stochastic general equilibrium models, method of moments, empirical likelihood, minimum constrast, minimum Hellinger distance. 



\section{Lista de ilustrações}

Figura B.1 - Distribuição de $\hat{\beta} \ldots \ldots \ldots \ldots$. . . . . . . . . . . . . 57

Figura B.2-Distribuiçãa de $\hat{\gamma} \ldots \ldots \ldots \ldots \ldots \ldots$

Figura B.3-Distribuição de $\hat{b} \ldots \ldots \ldots \ldots$. . . . . . . . . . . . . 59

Figura B.4-Distribuição de $\hat{\rho} \ldots \ldots \ldots \ldots$. . . . . . . . . . . . . 60

Figura B.5-Distribuição de $\hat{\sigma} \ldots \ldots \ldots \ldots$. . . . . . . . . . . . 61 


\section{Lista de tabelas}

Tabela B.1 - Parâmetros verdadeiros . . . . . . . . . . . . . . . . . . . 49

Tabela B.2-Médias das condições de momento . . . . . . . . . . . . . . . . . . . 49

Tabela B.3-Correlação entre as condições de momento . . . . . . . . . . . . . . . . 50

Tabela B.4 - Testes J, LM e LR de sobreidentificação - Métodos baseados em momentos 51

Tabela B.5-Estatísticas de $\hat{\beta} \ldots \ldots \ldots \ldots \ldots$. . . . . . . . . . . . . 52

Tabela B.6-Estatísticas de $\hat{\gamma} \ldots \ldots \ldots \ldots \ldots \ldots$

Tabela B.7-Estatísticas de $\hat{b} \ldots \ldots \ldots \ldots \ldots \ldots$

Tabela B.8-Estatísticas de $\hat{\rho} \ldots \ldots \ldots \ldots \ldots \ldots$

Tabela B.9-Estatísticas de $\hat{\sigma} \ldots \ldots \ldots \ldots \ldots \ldots$ 


\section{Sumário}

INTRODUÇÃo $\ldots \ldots \ldots \ldots \ldots \ldots \ldots \ldots \ldots$

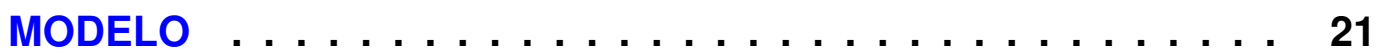

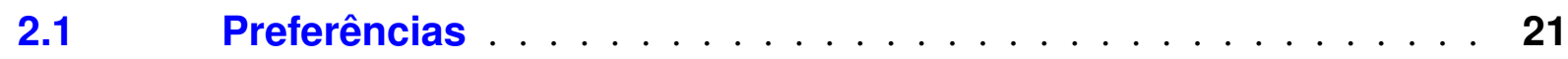

2.2 Tecnologia e produção $\ldots \ldots \ldots \ldots \ldots \ldots$

$2.3 \quad$ Leis de movimento e factibilidade . . . . . . . . . . . . . . 22

2.4 Problemas de maximização e equilíbrio competitivo . . . . . . 22

$2.5 \quad$ Estado estacionário e funções políticas . . . . . . . . . . . 23

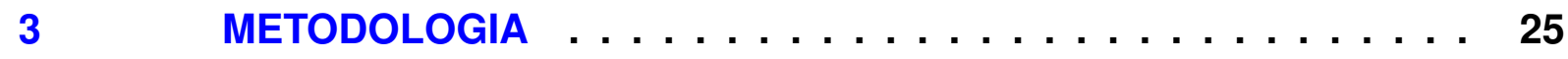

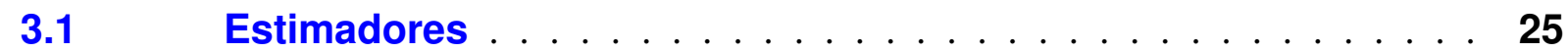

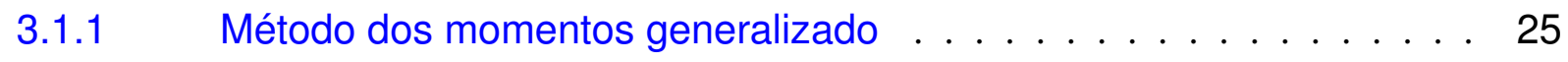

3.1.2 Verossimilhança empírica e mínimo contraste generalizados . . . . 26

3.1.3 Máxima verossimilhança e inferência bayesiana . . . . . . . . . . . 31

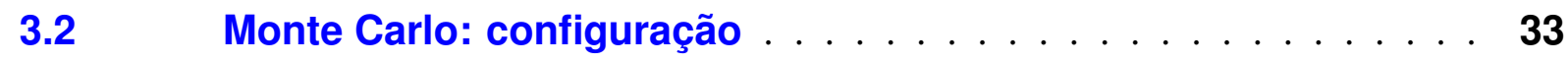

$4 \quad$ RESULTADOS $\ldots \ldots \ldots \ldots \ldots \ldots \ldots \ldots$

$5 \quad$ CONCLUSÃo $\ldots \ldots \ldots \ldots \ldots \ldots \ldots \ldots \ldots \ldots$

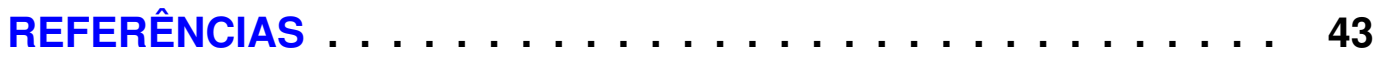

APÊNDICE A - CONDIÇÕES DE MOMENTO . . . . . . . 47

APÊNDICE B - TABELAS E FIGURAS . . . . . . . . . 49 



\section{Introdução}

Modelos econômicos e estatísticos, em especial modelos de equilíbrio geral dinâmico e estocástico (dynamic stochastic general equilibrium - DSGE), são suscetíveis a problemas de especificação visto que consistem em simplificações (às vezes notadamente fortes) da realidade. Omissão de variáveis relevantes, formas funcionais incorretas e hipóteses imprecisas sobre a distribuição dos dados são equívocos comuns e muitas vezes ocorrem simultaneamente nos procedimentos de estimação e previsão (MAASOUMI, 1990). Outros elementos como aproximações e transformações do modelo original muitas vezes acabam agravando o problema por gerarem mais distorções. Desta forma, métodos robustos de estimação com boa performance nos casos em que o modelo utilizado apresenta desvios da "especificação correta" são desejados (ANTOINE; DOVONOV, 2017). Por boa performance entende-se que o estimador é robusto em casos de má-especificação. Neste contexto, robustez significa insensibilidade a pequenos desvios das hipóteses adotadas, tal como definido em Huber e Ronchetti (2009). Os problemas de má-especificação podem ser de natureza global ou local.

No contexto de modelos baseados em condições de momento, má-especificação global ocorre quando as condições de momento populacionais não são satisfeitas, independentemente do tamanho da amostra, e má-especificação local ocorre quando tais condições não são satisfeitas em certos intervalos da amostra, desaparecendo assintoticamente (ANTOINE; DOVONOV, 2017). Em um contexto mais geral, podemos pensar que a má-especificação global relaciona-se com a adotação de alguma hipótese que não é satisfeita no total ou em proporção fixa das realizações e a má-especificação local estaria associada a desvios pontuais que assintoticamente perdem importância. Um exemplo para o primeiro tipo é assumir uma distribuição equivocada para o processo gerador de dados. Para o segundo, podemos pensar na presença de outliers pontuais na amostra, decorrente de contaminação dos dados utilizados, por exemplo. Note que nestes exemplos assumimos que a fonte da má-especificação pode surgir tanto do próprio modelo teórico considerado quanto da "qualidade" dos dados utilizados. Ambos os problemas de especificação estão presentes no contexto de estimação de modelos DSGE.

Na literatura atual sobre estimação de modelos DSGE, observamos duas abordagens distintas, tal como destacado por Riscado (2012). A primeira, consiste em utilizar o princípio da verossimilhança. Essa abordagem teve origem em Sargent (1989) que, ao linearizar as condições de equilíbrio ao redor do estado estacionário, obteve aproximações para as funções políticas do modelo, o que permitiu que a função de verossimilhança pudesse ser escrita. Para obtenção da verossimilhança, recorre-se ao filtro de Kalman, caso seja escolhida uma forma linear com processo estocástico com distribuição normal, ou ao filtro de partículas, caso seja escolhida uma forma não-linear e/ou outra distribuição. Obtida a verossimilhança, procede-se com a estimação dos parâmetros por meio de inferência clássica maximizando a função de verossimilhança (maximum likelihood - ML) ou por meio de inferência bayesiana (Bayesian inference - BI) obtendo a 
distribuição a posteriori dos parâmetros a partir da função de verossimilhança e da distribuição a priori dos parâmetros (RISCADO, 2012).

A outra abordagem apoia-se na classe de estimadores baseados em momentos que utiliza um conjunto de condições de momento geradas a partir das condições de primeira ordem do modelo, das hipóteses sobre a economia e dos choques que a atingem. Hansen e Singleton (1982) foram os primeiros a utilizar o método dos momentos generalizado (generalized method of moments GMM), pertencente à classe de estimadores baseados em momentos, visando estimar e testar equações de Euler. Dentre os primeiros trabalhos que utilizaram GMM para estimar modelos DSGE estão Christiano e Eichenbaum (1992), Burnside, Eichenbaum e Rebelo (1993) e Braun (1994). De acordo com Riscado (2012) e Ruge-Murcia (2013), entre as vantagens da estimação usando GMM em relação a estimação usando ML (e BI) estão: $(i)$ exigir menor quantidade de restrições para a distribuição dos dados e (ii) requerer menor capacidade computacional e, consequentemente, menos tempo.

Fernandez-Villaverde (2009) destaca que apesar das vantagens da aplicação do método bayesiano de estimação, abordagens não-paramétricas e semiparamétricas se enquadram mais naturalmente na abordagem da inferência clássica, visto que estimadores como GMM ou estimadores de verossimilhança empírica são diretamente relacionados às condições de primeira ordem e às equações de equilíbrio dos modelos DSGE. Ruge-Murcia (2007), ao comparar técnicas comuns de estimação de modelos DSGE usando dados simulados, concluiu que métodos baseados em momentos, mais especificamente GMM e métodos dos momentos simulados (simulated method of moments - SMM) obtiveram melhores resultados em relação ao estimador ML em termos de velocidade de estimação e robustez à problemas de especificação. Ruge-Murcia (2013) mostrou que GMM e SMM obtiveram estimações precisas para os parâmetros do modelo utilizado, mesmo em pequenas amostras e independentemente da matriz de ponderação utilizada. Entretanto, o autor destaca que uma amostra pequena pode comprometer a inferência estatística.

O objetivo deste trabalho é analisar a performance de estimadores baseados em momentos pertencentes às famílias verossimilhança empírica generalizada (generalized empirical likelihood - GEL) e mínimo contraste generalizado (generalized minimum contrast - GMC) na estimação de modelos DSGE, tendo como benchmark os estimadores GMM, ML e BI. Trabalharemos com um modelo de ciclos reais de negócios (real business cycle - RBC), que pode ser considerado o núcleo dos modelos DSGE atuais, possui dificuldades similares e menor número de parâmetros, o que facilita a análise. Verificamos por meio de experimentos de Monte Carlo se os estimadores estudados geram resultados satisfatórios em termos de viés e eficiência nas situações em que o modelo está corretamente especificado e damos ênfase à análise de robustez nas situações em que má-especificações local e global estão presentes, observando viés, erro quadrático médio (EQM), erro absoluto médio (EAM) e as distribuições das estimativas geradas por cada estimador. Os casos de má-especificação tratados abordam erro da distribuição assumida para o choque de produtividade e contaminação dos dados por outliers.

Dois estimadores baseados em momentos foram inicialmente considerados na estimação de 
modelos DSGE em Riscado (2012). Com o objetivo de mostrar uma inferência válida diferente da máxima verossimilhança, a autora estimou um modelo DSGE a partir de GMM e exponentially tilted empirical likelihood (ETEL). Dentre os resultados iniciais estão que o estimador ETEL não obteve resultados tão próximos dos valores verdadeiros quanto o estimador GMM e, além disso, os resultados do ETEL apresentaram maior desvio-padrão. Os dois estimadores tiveram dificuldades para lidar com a identificação dos parâmetros associados à curvatura da função utilidade. A autora incentiva a continuidade de pesquisas nesse campo devido às vantagens apresentadas pela verossimilhança empírica, tais como: ( $i$ ) uso direto das condições de equilíbrio do modelo, não sendo necessário computar a função política; (ii) flexibilidade quanto a adoção da hipótese de distribuição normal para o processo estocástico da economia e (iii) preservação da estrutura não-linear das condições de equilíbrio do modelo.

Analisando outro problema de pesquisa, Laurini e Hotta (2015) utilizaram alguns dos estimadores baseados em momentos considerados neste trabalho na estimação de equações diferenciais estocásticas utilizando dados simulados e efetivos da taxa de juros de curto prazo. Os autores concluíram que os resultados obtidos por estimadores das famílias GEL e GMC são superiores, em termos de viés e erro quadrático médio, aos resultados obtidos a partir de estimadores GMM (dois estágios, iterativo e continuous updating), estes frequentemente utilizados na literatura. O estimador ETEL obteve os melhores resultados e isso guarda relação com as suas boas propriedades de robustez em casos de modelos com erro de especificação, um problema recorrente na estimação de equações diferenciais estocásticas devido a necessidade de recorrer a discretizações.

Dentre os principais resultados deste trabalho, estão: $(i)$ o estimador verossimilhança empírica (empirical likelihood - EL) - assim como sua versão com condições de momentos suavizadas (SEL) - e a inferência bayesiana (BI) foram, nesta ordem, os que obtiveram os melhores desempenhos, inclusive nos caso de especificação incorreta; (ii) os estimadores continuous updating empirical likelihood (CUE), minimum Hellinger distance (HD), exponential tilting (ET) e suas versões suavizadas apresentaram desempenho comparativo intermediário; (iii) o desempenho dos estimadores ETEL, exponential tilting Hellinger distance (ETHD) e suas versões suavizadas foi bastante comprometido pela ocorrência de estimativas atípicas; (iv) as versões com e sem suavização das condições de momento dos estimadores das famílias GEL/GMC apresentaram desempenhos muito semelhantes; (iv) os estimadores GMM, principalmente no caso sobreidentificado, e ML apresentaram desempenhos inferiores a seus concorrentes.

Este trabalho está estruturado em mais quatro capítulos além desta introdução e do apêndice. No capítulo 2 o modelo utilizado nas estimações é apresentado. O capítulo 3 apresenta com detalhes os estimadores analisados no trabalho e o desenho dos experimentos de Monte Carlo realizados. O capítulo 4 discute os resultados. A conclusão está no capítulo 5. Por fim, no Apêndice estão a derivação das condições de momento utilizadas nos métodos baseados em momentos e as tabelas e figuras que sumarizam os resultados. 



\section{Modelo}

Este capítulo apresenta o modelo utilizado neste trabalho. Nós trabalharemos com uma versão "um consumidor-um produtor" do modelo RBC, parecido com o modelo proposto por Hansen (1985) e com o modelo de crescimento estocástico padrão utilizado na análise de RugeMurcia (2013). A versão que utilizamos possui vetor de preços (salário real e taxa real de juros, no caso) e conta com o problema de maximização da firma. Em vez de a função de utilidade instantânea ser logarítmica e ter o consumo como único argumento, utilizamos uma versão na qual as preferências de consumo seguem estrutura de aversão relativa ao risco constante (constant relative risk aversion - CRRA) ${ }^{2.1}$ e a desutilidade do trabalho é linear, tal como definido no modelo usado por Ruge-Murcia (2013). Além do fato de ser bastante difundido na literatura, as principais vantagens de se trabalhar com o este modelo advém do fato dele ser a base dos modelos DSGE, possuir os aspectos (e dificuldades) dos modelos DSGE mais complexos e possuir poucos parâmetros, o que contribui para a análise dos resultados. A seguir a estrutura do modelo é detalhada.

\subsection{Preferências}

Suponha que a população da economia seja idêntica e que as preferências do consumidor representativo sejam caracterizadas pela função de utilidade instantânea

$$
u\left(c_{t}, n_{t}\right)=\frac{c_{t}^{1-\gamma}}{1-\gamma}+b\left(1-n_{t}\right), \quad \gamma, b>0
$$

na qual $c_{t}$ é consumo no período t, $n_{t}$ é quantidade de horas trabalhadas no período t, $\gamma$ é o parâmetro de aversão relativa ao risco (curvatura da função utilidade) e $b$ mensura a desutilidade do trabalho (ou a utilidade do lazer). A dotação de tempo e o tamanho da população são constantes e normalizados em 1.

\subsection{Tecnologia e produção}

Suponha a existência de um único bem perecível na economia, $y_{t}$, cuja produção pode ser descrita pela função

$$
y_{t}=f\left(k_{t}, n_{t}, z_{t}\right)=z_{t} k_{t}^{\alpha} n_{t}^{1-\alpha}
$$

na qual $\alpha \in(0,1)$ é o parâmetro da elasticidade do produto em relação ao capital, $k_{t}$ é estoque de capital em t e $z_{t}$ é um choque exógeno de produtividade ocorrido em t. Como esta função é homogênea de grau um, os retornos de escala são constantes.

$\overline{2.1}$ Note que a utilidade logarítmica é um caso especial de utilidade CRRA (quando o coeficiente de aversão relativa é igual a 1). 


\subsection{Leis de movimento e factibilidade}

Considere que o nível tecnológico (produtividade) que aparece na função de produção seja descrito por

$$
\ln z_{t}=\rho \ln z_{t-1}+\varepsilon_{z, t}, \quad \varepsilon_{z, t} \sim\left(0, \sigma^{2}\right)
$$

em que $\rho \in(-1,1)$ indica que a tecnologia segue um processo estacionário e $\varepsilon_{z, t}$ é um choque independente e identicamente distribuído (iid).

Suponha a existência de um estoque de capital inicial maior do que zero, isto é, $k_{0}>0$, e que o estoque de capital tenha a seguinte dinâmica

$$
k_{t+1}=i_{t}+(1-\delta) k_{t}
$$

em que $\delta \in[0,1]$ é taxa de depreciação do capital e $i_{t}$ é investimento feito no período t. Desta forma, a economia deverá respeitar a condição de factibilidade dada por

$$
c_{t}+i_{t}=w_{t} n_{t}+r_{t} k_{t+1}+\pi_{t}
$$

em que $w_{t}$ é salário real, $r_{t}$ é taxa real de juros e $\pi_{t}$ é lucro da firma.

\subsection{Problemas de maximização e equilíbrio competitivo}

Nesta economia, o consumidor representativo resolve o problema de maximização

$$
\max _{\left\{c_{t}, n_{t}, k_{t+1}\right\}_{t=0}^{\infty}} \mathbb{E}_{0} \sum_{t=0}^{\infty} \beta^{t} u\left(c_{t}, n_{t}\right)
$$

sujeito a (2.1), (2.2), (2.3), (2.4) e dado $k_{0}>0$. A firma representativa, por sua vez, resolve o problema de maximização estático

$$
\max _{y_{t}, n_{t}, k_{t+1}} \pi_{t}
$$

em que $\pi_{t}=y_{t}-w_{t} n_{t}-r_{t} k_{t+1}$, sujeito a (2.1), (2.2) e (2.3).

As escolhas ótimas de consumo e de oferta de trabalho são dadas pelas condições de primeira ordem

$$
\begin{gathered}
c_{t}^{\gamma}=\frac{w_{t}}{b} \\
c_{t}^{-\gamma}=\beta \mathbb{E}_{t}\left[\left(1-\delta+r_{t+1}\right) c_{t+1}^{-\gamma}\right]
\end{gathered}
$$

que são, respectivamente, relação intratemporal entre consumo e trabalho e equação de Euler do consumo. As condições de primeira ordem da firma são dadas por

$$
\begin{gathered}
r_{t}=\alpha z_{t} k_{t}^{\alpha-1} n_{t}^{1-\alpha} \\
w_{t}=(1-\alpha) z_{t} k_{t}^{\alpha} n_{t}^{-\alpha}
\end{gathered}
$$


ou seja, são os preços da economia (taxa de juros e salário, respectivamente). Note que o produto $y_{t}$ é o numerário da economia, isto é, $r_{t}$ e $w_{t}$ estão normalizados pelo preço do único bem produzido.

O equilíbrio competitivo desta economia é dado pelo sequência de preços $\left\{w_{t}, r_{t}\right\}_{t=0}^{\infty}$ e pela sequência de alocações da firma $\left\{k_{t+1}^{d}, n_{t}^{d}, y_{t}\right\}_{t=0}^{\infty}$ e do consumidor $\left\{c_{t}, i_{t}, k_{t+1}^{s}, n_{t}^{s}\right\}_{t=0}^{\infty}$ tais que utilidade do consumidor e lucro da firma são maximizados e os mercados se ajustam, ou seja, $y_{t}=c_{t}+i_{t}$ (mercado de bens), $k_{t+1}=k_{t+1}^{d}=k_{t+1}^{s}$ (mercado de capital) e $n_{t}=n_{t}^{d}=n_{t}^{s}$ (mercado de trabalho). Nas equações anteriores, os sobrescritos $d$ e $s$ indicam demanda e oferta do insumo de produção em questão, respectivamente.

\subsection{Estado estacionário e funções políticas}

Após a obtenção dos valores de estado estacionário, a sequência de alocações ótima é gerada a partir das funções políticas. McCandless (2008) destaca que, mesmo com o avanço computacional, para obtenção das funções políticas é necessário recorrer a algum tipo de aproximação quando o modelo é mais complicado e a dimensão de variáveis de estado aumenta. Nestas situações, recorre-se a duas possibilidades: $(i)$ aproximações log-lineares das equações que descrevem o equilíbrio competitivo e (ii) uso de programação dinâmica linear quadrática após obter aproximação quadrática da função objetivo combinada com linearização das restrições orçamentárias (MCCANDLESS, 2008).

O método proposto por Uhlig (1999), um dos mais utilizados, se enquadra na primeira possibilidade. Este método dispensa o cálculo de derivadas e apresenta o resultado na forma de diferença logarítmica das variáveis, ou seja, como desvios percentuais do estado estacionário. Os resultados de estado estacionário costumam ser utilizados para simplificar as versões log-linearizadas das equações do modelo. A partir destas equações log-linearizadas, procede-se escrevendo o modelo na forma matricial relacionando todas as variáveis, tanto contemporaneamente quanto os valores defasados e adiantados, de modo a "fechar" o sistema e, finalmente, obter as funções políticas (MCCANDLESS, 2008). Existem outros métodos que podem ser utilizados para cumprimento desta etapa a partir das versões log-linearizadas das equações do modelo - ver Blanchard e Khan (1980) e Sims (2002), por exemplo. Para mais detalhes sobre estes procedimentos e também sobre a obtenção da variância das variáveis (que depende da variância do choque de produtividade) ver Canova (2007), McCandless (2008) e DeJong e Dave (2011). 



\section{Metodologia}

\subsection{Estimadores}

\subsubsection{Método dos momentos generalizado}

Hansen (1982) derivou o estimador do método dos momentos generalizado (generalized method of moments - GMM) e demonstrou suas propriedades para grandes amostras. Seja $h\left(x_{t}, \theta_{0}\right)$ um vetor de condições de momento em que $\theta_{0}$ é o vetor de parâmetros verdadeiros e $x_{t}$ são as variáveis aleatórias (VAs). As condições de momento devem satisfazer a restrição

$$
\mathbb{E}\left[h\left(x_{t}, \theta_{0}\right)\right]=0 .
$$

O análogo amostral de $h\left(x_{t}, \theta_{0}\right)$ é dado por

$$
g\left(x_{t}, \theta\right) \equiv \frac{1}{T} \sum_{t=1}^{T} h\left(x_{t}, \theta\right)
$$

em que $\theta$ é um vetor de parâmetros desconhecidos pertencente ao espaço paramétrico $\Theta$ e $T$ representa o tamanho da amostra. Assim, o estimador GMM é definido por

$$
\hat{\theta}_{G M M}=\underset{\theta \in \Theta}{\arg \min } g\left(x_{t}, \theta\right)^{\prime} W g\left(x_{t}, \theta\right)
$$

em que $W$ é uma matriz de ponderação positiva definida cuja forma ótima corresponde ao inverso da matriz de variância assintótica (HAMILTON, 1994). Contudo, a matriz de variância assintótica é função dos parâmetros do modelo e, desta forma, precisa ser estimada. Esta estimação pode ser realizada por meio dos procedimentos desenvolvidos por Newey e West (1987) e Andrews (1991) que definiram estimadores consistentes para a variância assintótica na presença de heteroscedasticidade e correlação serial (estimadores HAC).

Se o sistema é sobreidentificado, isto é, o número de condições de momento é maior do que o número de parâmetros, pode-se empregar o teste J de sobreidentificação proposto por Hansen (1982) que é dado por

$$
\left[\sqrt{T} g\left(x_{t}, \hat{\theta}_{G M M}\right)\right]^{\prime} \hat{S}^{-1}\left[\sqrt{T} g\left(x_{t}, \hat{\theta}_{G M M}\right)\right] \stackrel{d}{\rightarrow} \chi_{p-q}^{2}
$$

em que $\hat{S}$ é a matriz HAC para variância assintótica e $p-q$ representa os graus de liberdade da distribuição qui-quadrado, sendo $p$ o número de momentos e $q$ o número de parâmetros. A hipótese nula é modelo bem especificado (condições de momento válidas).

O GMM em dois estágios (two-step GMM - 2SGMM), procedimento proposto inicialmente por Hansen (1982), foi a forma de implementação utilizada neste trabalho. ${ }^{3.1}$ Nele escolhe-se

3.1 Devido a problemas de implementação computacional não foi possível utilizar as versões iterativa e continuous updating do GMM. 
uma matriz de ponderação $W$ inicial, geralmente a matriz identidade. A partir deste primeiro estágio, calcula-se a matriz HAC $\hat{S}\left(\hat{\theta}_{1}\right)$, em que $\hat{\theta}_{1}$ é o vetor de parâmetros estimado no primeiro estágio. O próximo estágio inicia-se utilizando a matriz obtida no primeiro estágio e se obtêm $\hat{\theta}_{2}$, isto é, o vetor de parâmetros estimado no segundo estágio.

\subsubsection{Verossimilhança empírica e mínimo contraste generalizados}

Verossimilhança empírica (EL). A verossimilhança empírica (empirical likelihood - EL), termo cunhado por Owen (1988), pode ser vista como uma estimação de máxima verossimilhança não-paramétrica (nonparametric maximum likelihood estimation - NPMLE). Seja $\left\{x_{t}\right\}_{t=1}^{T}$ uma sequência de dados iid em que $x_{t}$ é distribuído com probabilidade desconhecida $\mu$. Definimos a função de log-verosimilhança não-paramétrica por

$$
\ell_{N P}\left(p_{1}, \ldots, p_{T}\right)=\sum_{t=1}^{T} \log p_{t}, \quad\left(p_{1}, \ldots, p_{T}\right) \in \triangle
$$

em que $\Delta$ denota um simplex $\left\{\left(p_{1}, \ldots, p_{T}\right): \sum_{t=1}^{T} p_{t}=1 ; p_{t} \geq 0, t=1, \ldots, T\right\}$. Isso pode ser interpretado como a log-verossimilhança de uma distribuição multinomial com suporte dado pelas observações empíricas $\left\{x_{t}\right\}_{t=1}^{T}$, mesmo se a distribuição $\mu$ de $x_{t}$ não seja multinomial (KITAMURA, 2006).

Owen (1991), Qin e Lawless (1994) e Imbens (1997) relacionaram a verossimilhança empírica com estimação baseada em momentos tomando uma condição de momento da forma

$$
\mathbb{E}\left[g\left(x_{t}, \theta\right)\right]=\int g(x, \theta) \mathrm{d} \mu=0, \quad \theta \in \Theta \subset \mathbb{R}^{q}
$$

em que $g \in \mathbb{R}^{q}$ é uma função conhecida, $q$ é o número de parâmetros e $\Theta$ é o espaço paramétrico. Combinando (3.2) e (3.3), temos que a função de log-verossimilhança não-paramétrica a ser maximizada é

$$
\ell_{N P}=\left\{\sum_{t=1}^{T} \log p_{t}: \sum_{t=1}^{T} p_{t}=1 ; \sum_{t=1}^{T} p_{t} g\left(x_{t}, \theta\right)=0\right\}
$$

em que $\left(\theta, p_{1}, \ldots, p_{T}\right) \in \Theta \times \Delta$ que maximiza $\ell_{N P}$ é chamado estimador de máxima verossimilhança empírica (KITAMURA, 2006). As probabilidades $p_{t}$ dão maior peso para as observações nas quais as condições de momento são satisfeitas (resultam zero ou valor próximo de zero) e menor peso para as observações nas quais as condições de momento não são satisfeitas (valores afastados de zero). Quando $p_{t}=\frac{1}{T}$, o estimador EL se reduz ao GMM.

Kitamura (2006) mostra que, após montado o lagrangeano associado à (3.4) e obtidas as condições de primeira ordem, obtém-se a seguinte expressão para o estimador EL de $\theta$ :

$$
\hat{\theta}_{E L}=\underset{\theta \in \Theta}{\arg \max } \min _{\gamma \in \mathbb{R}^{q}}-\sum_{t=1}^{T} \log \left(1+\gamma^{\prime} g\left(x_{t}, \theta\right)\right)
$$

em que $\gamma$ é um vetor com multiplicadores de Lagrange. 
Verossimilhança empírica generalizada (GEL) e os estimadores EL, ET e CUE. A classe de estimadores de verossimilhança empírica generalizada (generalized empirical likelihood GEL), proposta inicialmente em Smith (1997), consiste em um arcabouço unificador que engloba o estimador EL e outros estimadores que compartilham uma estrutura comum, sendo assintoticamente equivalente ao $2 \mathrm{SGMM}$ e possuindo propriedades assintóticas de ordem superiores melhores que as deste, além de melhor performance para o caso de pequenas amostras (NEWEY; SMITH, 2004; KITAMURA, 2006; SMITH, 2011).

Seja $\rho(v)$ uma função cujo domínio seja convexo e pertença a um intervalo aberto $\Upsilon$ que contenha o zero. Desta forma, o estimador GEL é expresso pelo problema de sela

$$
\hat{\theta}_{G E L}=\underset{\theta \in \Theta}{\arg \min } \sup _{\lambda \in \Lambda} \sum_{t=1}^{T} \rho\left(\lambda^{\prime} g\left(x_{t}, \theta\right)\right)
$$

em que $\Lambda=\left\{\lambda: \lambda^{\prime} g\left(x_{t}, \theta\right) \in \Upsilon\right\}$ (NEWEY; SMITH, 2004; ANATOLYEV; GOSPODINOV, 2011). A escolha da função $\rho(v)$ define os seguintes estimadores: 1) verossimilhança empírica (EL) de Owen (1988), Qin e Lawless (1994) e Imbens (1997): $\rho(v)=\ln (1-v)$; 2) exponential tilting (ET) de Kitamura e Stutzer (1997) e Imbens, Johnson e Spady (1998): $\rho(v)=\exp (v) ; 3$ ) continuous updating (CUE) de Hansen, Heaton e Yaron (1996): $\rho(v)=-(1+v)^{2} / 2$ (NEWEY; SMITH, 2004; SCHENNACH, 2007; SMITH, 2011).

Mínimo contraste generalizado (GMC) e sua relação com o GEL. O estimador GEL pode ser considerado um caso especial de mínimo contrate generalizado (generalized minimum contrast - GMC), generalização da ideia contida em Wolfowitz (1957) proposta por Bickel et al. (1993). Seguindo Kitamura (2006), considere uma função geral de divergência entre duas medidas de probabilidade, $P$ e $Q$, da seguinte forma

$$
D(P, Q)=\int \phi\left(\frac{\mathrm{d} P}{\mathrm{~d} Q}\right) \mathrm{d} Q
$$

em que $\phi(\bullet)$ é uma função convexa. Uma destas medidas costuma seguir uma distribuição não-paramétrica dos dados e a outra corresponde a uma distribuição estatística associada a algum modelo. Seja $x_{t} \in \mathbb{R}^{n}$ VAs iid, sendo $n$ o número de VAs. Considere um modelo que siga as condições de momento como em (3.3). Seja $\mathcal{M}$ o conjunto de todas as medidas de probabilidade em $\mathbb{R}^{n}$ e defina

$$
\mathcal{P}=\bigcup_{\theta \in \Theta} \mathcal{P}(\theta) \quad \text { em que } \quad \mathcal{P}(\theta)=\left\{P \in \mathcal{M}: \int g\left(x_{t}, \theta\right) \mathrm{d} P=0\right\},
$$

isto é, $\mathcal{P}$ representa um modelo estatístico e é o conjunto de todas as medidas de probabilidade compatíveis com a restrição de momento (3.3). O modelo $\mathcal{P}$ está corretamente especificado apenas se incluir as verdadeiras medidas de probabilidade $\mu$. Deste modo, o problema de otimização associado ao GMC é dado por

$$
\inf _{\theta \in \Theta} \inf _{P \in \mathcal{P}} D(P, \mu) .
$$


Após o desenvolvimento algébrico do problema de otimização, Kitamura (2006) chega ao seguinte resultado que define o estimador GMC para o caso amostral:

$$
\hat{\theta}_{G M C}=\left\{\underset{\theta \in \Theta}{\arg \min i n f} \frac{1}{T} \sum_{t=1}^{T} \phi\left(t p_{t}\right): \sum_{t=1}^{T} p_{t}=1 ; \sum_{t=1}^{T} p_{t} g\left(\theta, x_{t}\right)=0\right\},
$$

em que $\phi$ é uma função convexa e cujo análogo conveniente para implementação computacional decorrente do teorema da dualidade presente em Borwein e Lewis (1991) é dado por

$$
\hat{\theta}_{G M C}=\underset{\theta \in \Theta}{\arg \min }\left\{\max _{\lambda, \gamma \in \mathbb{R}^{n}}\left[\lambda-\frac{1}{T} \sum_{t=1}^{T} \phi^{*}\left(\lambda+\gamma^{\prime} g\left(\theta, x_{t}\right)\right)\right]\right\}
$$

em que $\lambda$ e $\gamma$ são vetores de multiplicadores de Lagrange e $\phi^{*}$ é um conjugado convexo da função $\phi .^{3.2}$ Após desenvolvimento algébrico do estimador (3.7), obtemos uma expressão que é equivalente à expressão (3.5) que define o estimador GEL. Os estimadores GEL e GMC compartilham propriedades análogas tais como, mesma distribuição assintótica, possibilidade de usar o valor da função objetivo para inferência e argumentos similares para realização de testes de sobreidentificação (KITAMURA, 2006).

Seguindo Corcoran (1998) e Newey e Smith (2004), o estimador de mínimo contraste (MC) $)^{3.3}$ é dado por

$$
\hat{\theta}_{M C}=\underset{\theta, p_{t}}{\arg \min } \sum_{t=1}^{T} h_{T}\left(p_{t}\right)
$$

em que $h_{T}\left(p_{t}\right)$ representa alguma função de contraste. Assumindo-se função de contraste da família Cressie e Read (1984) de discrepâncias dada por

$$
h_{T}\left(p_{t}\right)=\frac{[\gamma(\gamma+1)]^{-1}\left(T p_{t}\right)^{\gamma+1}-1}{T}
$$

em que $\gamma$ é um parâmetro de indexação, obtemos os estimadores da classe de estimadores GEL, que também pertencem a classe de estimadores GMC, atribuindo valores específicos para $\gamma$ : (1) EL: $\gamma=0$; (2) ET: $\gamma=-1$; (3) CUE: $\gamma=1$ (CORCORAN, 1998; NEWEY; SMITH, 2004; SCHENNACH, 2007).

Exponentially tilted empirical likelihood (ETEL). Schennach (2007) propôs um estimador que mescla o estimador EL, que possui boas propriedades assintóticas no caso de modelos corretamente especificados, com o estimador ET, que possui melhor comportamento sob especificação incorreta, denominado exponentially tilted empirical likelihood (ETEL) e que pode ser definido com a expressão

$$
\hat{\theta}_{\text {ETEL }}=\underset{\theta \in \Theta}{\arg \min }\left[\frac{1}{T} \sum_{t=1}^{T} \tilde{h}\left(\hat{p}_{t}(\theta)\right)\right]
$$

\footnotetext{
3.2 Para uma função convexa $f(x)$, seu conjugado convexo $f^{*}$ é dado por $f^{*}(y)=\sup _{x}[x y-f(x)]$

3.3 Neste trabalho, discrepância e contraste são tratados como sinônimos.
} 
em que $\hat{p}_{t}(\theta)$ é a solução de

$$
\min _{\left\{p_{t}\right\}_{t=1}^{T}}\left\{\frac{1}{T} \sum_{t=1}^{T} h\left(p_{t}\right): \sum_{t=1}^{T} p_{t}=1 ; \sum_{t=1}^{T} p_{t} g\left(x_{t}, \theta\right)=0\right\}
$$

$\operatorname{com} \tilde{h}\left(p_{t}\right)=-\ln \left(T p_{t}\right)$ e $h\left(p_{t}\right)=T p_{t} \ln \left(T p_{t}\right)$.

Este estimador exibe as mesmas vantagens de ambos estimadores que o definem, ou seja, possui o mesmo baixo viés e a mesma variância do estimador EL em caso de modelo corretamente especificado e evita as dificuldades relacionadas ao estimador EL em caso de especificação incorreta ao conter em sua estrutura o estimador ET (SCHENNACH, 2007). Mais especificamente, o ETEL utiliza o método ET para obter $\hat{p}_{t}(\theta)$ e o método EL para obter $\hat{\theta}$ (LAURINI; HOTTA, 2015).

Estimador de mínima distância de Hellinger (HD). De acordo com Kitamura, Otsu e Evdokimov (2013), o sentido de buscar uma estimação robusta a pequenas perturbações decorre do fato dos dados poderem apresentar desvios da distribuição considerada para a modelagem. A distância de Hellinger pode ser utilizada para medir a divergência entres distribuições, tal como elucidado por (3.6), sendo definida como

$$
H\left(P_{\theta}, P\right)=\sqrt{\int\left(p_{\theta}^{\frac{1}{2}}(x)-p^{\frac{1}{2}}(x)\right)^{2} \mathrm{~d} x},
$$

em que $P_{\theta}$ e $P$ são medidas de probabilidade com densidades $p_{\theta}$ e $p$, respectivamente.

Beran (1977) discute o uso de estimadores que minimizam a distância de Hellinger para os procedimentos paramétrico e não-paramétrico sendo assintoticamente semelhantes ao ML e robusto a desvios da especificação correta. Kitamura, Otsu e Evdokimov (2013) obtém um estimador associando minimização da distância de Hellinger e condições de momento que é conveniente computacionalmente com propriedades de robustez minimax. O estimador de mínima distância de Hellinger (minimum Hellinger distance - HD) é eficiente semiparametricamente e robusto na vizinhança do verdadeiro $P_{\theta}$ e pode ser apresentado como

$$
\hat{\theta}_{H D}=\underset{\theta \in \Theta}{\arg \min } H\left(P_{\theta}, \hat{P}\right) \Rightarrow \hat{\theta}_{H D}=\underset{\theta \in \Theta}{\arg \min } \int\left(p_{\theta}^{\frac{1}{2}}(x)-\hat{p}^{\frac{1}{2}}(x)\right)^{2} \mathrm{~d} x,
$$

em que $\hat{p}$ é um estimador de densidade não-paramétrico para $p$, tal como um estimador kernel, e $\hat{P}$ é o estimador correspondente para a medida de probabilidade de $x$. Este estimador é assintoticamente equivalente ao ML e, desta forma, eficiente se as hipóteses do modelo são satisfeitas. Além disso, se $\gamma=-\frac{1}{2}$ em (3.8) obtemos o estimador HD (CORCORAN, 1998) e, portanto, temos que ele pertence às classes de estimadores GEL e GMC (KITAMURA; OTSU; EVDOKIMOV, 2013).

Exponential tilting Hellinger distance (ETHD). Antoine e Dovonov (2017) mesclaram o estimador HD, que possui boas propriedades assintóticas e bom desempenho sob especificação correta e má-especificação local, com o estimador ET, que possui boas propriedades sob 
má-especificação global. Com isso, eles geraram o estimador denominado exponential tilting Hellinger distance (ETHD) que é eficiente sob especificação correta e robusto a má-especificações local e global em modelos com condições de momento. O estimador ETHD é definido por

$$
\hat{\theta}_{E T H D}=\underset{\theta \in \Theta}{\arg \min } H(\hat{p}(\theta), \hat{p})
$$

em que $\hat{p}(\theta)$ é a solução de

$$
\min _{\left\{p_{t}\right\}_{t=1}^{T}}\left\{\frac{1}{T} \sum_{t=1}^{T} p_{t} \log T p_{t}: \sum_{t=1}^{T} p_{t} g\left(x_{t}, \theta\right)=0 ; \sum_{t=1}^{T} p_{t}=1\right\}
$$

Note que o estimador ETHD combina a função de discrepância $H(\bullet)$ do estimador HD definida em (3.9) com as probabilidades implícitas do estimador ET (ANTOINE; DOVONOV, 2017).

\section{Verossimilhança empírica generalizada suavizada (SGEL) e os estimadores SEL, SET,} SCUE, SETEL, SHD e SETHD. Os estimadores da classe verossimilhança empírica generalizada com condições de momento suavizadas (smoothed generalized empirical likelihood - SGEL) $)^{3.4}$, retratados em Smith (1997), Anatolyev (2005), Anatolyev e Gospodinov (2011), consegue lidar com os problemas de dados com dependência temporal e condições de momento heteroscedásticas e serialmente correlacionadas ao substituir $g\left(x_{t}, \theta\right)$ por uma versão suavizada dada por

$$
g^{w}\left(x_{t}, \theta\right)=\sum_{j=-m}^{m} \omega(j) g\left(x_{t-j}, \theta\right)
$$

em que $\omega(j)$ é uma ponderação normalizada para 1 definida a partir de uma função kernel, similarmente ao que ocorre na classe de estimadores HAC propostos por Newey e West (1987) e Andrews (1991), e $m$ é uma defasagem para truncamento que reflete a ordem de correlação serial em $g\left(x_{t}, \theta\right)$. O uso de condições de momento suavizadas pode ser útil inclusive para melhorar o desempenho em termos de viés mesmo no caso em que os dados sejam iid. Utilizando condições de momento suavizadas da forma $\sum_{t=1}^{T} p_{t} g^{w}\left(x_{t}, \theta\right)=0$ obtemos versões com momentos suavizados dos estimadores EL, ET, CUE, ETEL HD, ETHD denominadas SEL, SET, SCUE, SETEL, SHD e SETHD.

Testes de especificação para estimadores GEL/GMC. Enquanto o teste J costuma ser utilizado para verificar a especificação da estimação GMM em casos sobreidentificados, nas estimações por meio de GEL e GMC, além deste teste também pode-se utilizar os testes multiplicador de Lagrange (LM) e razão de verossimilhança (LR) que consideram os multiplicadores de Lagrange presentes na equação (3.5). As estatísticas J, LM e LR são assintoticamente equivalentes de modo que os testes LM e LR possuem distribuição assintótica qui-quadrado, assim como o teste $\mathrm{J}$ (SMITH, 2011).

\footnotetext{
3.4 A distinção entre GEL e SGEL está presente em Anatolyev (2005) e Anatolyev e Gospodinov (2011).
} 


\subsubsection{Máxima verossimilhança e inferência bayesiana}

Os métodos que utilizam o princípio da verossimilhança impõem mais restrições ao assumir uma distribuição específica para os dados analisados. Para a estimação de modelos DSGE utilizando esta vertente, o primeiro passo é reescrever o modelo na forma de espaço de estados em virtude da necessidade de avaliar a função de verossimilhança de um modelo que possui variáveis não observáveis. Esta metodologia exige que o número de equações de medida seja idêntico ou inferior ao número de equações de estado, ou seja, que o número de variáveis observáveis seja no máximo idêntico ao número de choques estruturais ou erros de medida adicionados. No caso do modelo RBC utilizado neste trabalho, como temos apenas um choque estrutural (do processo tecnológico, $\varepsilon_{z, t}$ ) poderemos utilizar apenas uma variável observável do modelo que, no caso, será o produto $\left(y_{t}\right)$. É comum na literatura recorrer à inclusão de erros de medida na equação de medida para que mais variáveis observáveis possam ser utilizadas na estimação. Entretanto, para manter o mesmo modelo em todas as estimações, procederemos com a utilização de apenas uma variável observada.

As matrizes usadas na representação em espaço de estados são baseadas na solução loglinearizada do modelo. Devido à log-linearização, as variáveis entrarão na estimação como desvio (percentual) do estado estacionário. Esta característica será indicada com “ ” em cima da variável considerada. A representação em espaço de estados que não considera a inclusão de erros de medida ${ }^{3.5}$ pode assumir a seguinte forma

$$
\begin{gathered}
\tilde{y}_{t}=H \tilde{\xi}_{t-1} \\
\tilde{\xi}_{t}=F(\theta) \tilde{\xi}_{t-1}+G(\theta) \varepsilon_{z, t} \\
\varepsilon_{z, t} \sim N\left(0, \sigma^{2}\right)
\end{gathered}
$$

em que $\tilde{y}_{t}$ denota um vetor de variáveis observáveis como desvios dos seus respectivos valores de estado estacionário (no nosso caso, apenas a série do produto), $\tilde{\xi}_{t}$ é um vetor com todas as variáveis do modelo também como desvio do estado estacionário de tamanho $m+s$, sendo $m$ o número de variáveis observáveis utilizadas na estimação e $s$ o número de variáveis de estado ou seja, $\tilde{\xi}_{t}^{\prime}=\left[\tilde{y}_{t}, \tilde{z}_{t}\right]$, em que $\tilde{z}_{t}$ é um vetor variáveis de estado (neste trabalho, apenas o desvio do estado estacionário do processo tecnológico). A matriz $H$ da equação de medida (3.10) fornece o mapeamento de todas as variáveis nas variáveis de estado e as matrizes $F(\theta)$ e $G(\theta)$ da equação de transição (3.11) contém as relações não-lineares entre os parâmetros do modelo obtidas por meio da log-linearização (solução) do modelo.

Como o processo estocástico - equação (3.12) - segue uma distribuição normal, procede-se com a obtenção da função de verossimilhança usando o filtro de Kalman que utiliza método recursivo para recuperar o estado de modo a minimizar o erro quadrático de previsão. Após a obtenção da função de verosimilhança, estima-se os parâmetros utilizando inferência clássica

3.5 Se a inclusão de erros de medida fosse considerada, a equação de medida tornaria-se $\tilde{y}_{t}=H \tilde{\xi}_{t-1}+J v_{t}$, em que $v_{t}$ é um vetor contendo os erros de medida e $J$ é uma matriz que relaciona estes erros com as variáveis observáveis. 
(máxima verossimilhança) maximizando a função de log-verossimilhança em relação aos parâmetros do modelo, ou utilizando inferência bayesiana ao combinar a função de verossimilhança com distribuição a priori dos parâmetros para obter a distribuição a posteriori. No primeiro, os parâmetros são estimados a partir da maximização da função de verossimilhança. No segundo, o objetivo é atribuir aos parâmetros probabilidades condicionadas nos dados observados possibilitando a incorporação de "conhecidos prévios" (distribuições a priori). O que distingue a análise bayesiana da clássica é a interpretação probabilística dada aos parâmetros e não aos dados. (DEJONG; DAVE, 2011).

Máxima verossimilhança (ML). O estimador ML de $\theta$ é dado por

$$
\hat{\theta}_{M L}=\underset{\theta \in \Theta}{\arg \max } \ell(\theta)
$$

em que $\ell(\theta)$ denota a função de log-verossimilhança dada por

$$
\begin{aligned}
\ell(\theta)=\ln \mathcal{L}\left(\tilde{y}_{t} \mid \theta\right)=-\frac{T}{2} & \ln (2 \pi)-\frac{1}{2} \ln \left|H P_{t \mid t-1} H^{\prime}\right| \\
& -\frac{1}{2} \sum_{t=1}^{T}\left(\tilde{y}_{t}-H \tilde{\xi}_{t \mid t-1}\right)^{\prime}\left(H P_{t \mid t-1} H^{\prime}\right)^{-1}\left(\tilde{y}_{t}-H \tilde{\xi}_{t \mid t-1}\right)
\end{aligned}
$$

sendo $P_{t \mid t-1}=\mathbb{E}\left(\tilde{\xi}_{t-1}-\tilde{\xi}_{t \mid t-1}\right)\left(\tilde{\xi}_{t-1}-\tilde{\xi}_{t \mid t-1}\right)^{\prime}$ uma matriz de variância-covariância. A logverossimilhança (3.13) foi escrita na forma de "decomposição do erro de previsão" e o processo de estimação consiste na minimização do terceiro termo desta equação (desconsiderando-se o sinal negativo). Para cada escolha de parâmetros, a função de verossimilhança é calculada por meio da decomposição do erro de previsão e as estimativas são atualizadas usando-se algum algoritmo de otimização (CANOVA, 2007).

Inferência bayesiana (BI). Este método combina a função de verossimilhança com uma distribuição a priori usando a regra de Bayes de modo a gerar uma distribuição a posteriori dos parâmetros. Ao usar a função de verossimilhança dá-se peso aos dados e ao usar uma distribuição a priori dá-se peso ao conhecimento prévio do pesquisador (DEJONG; DAVE, 2011). A regra de Bayes é dada por

$$
\pi\left(\theta \mid \tilde{y}_{t}\right)=\frac{\mathcal{L}\left(\tilde{y}_{t} \mid \theta\right) \pi(\theta)}{\int \mathcal{L}\left(\tilde{y}_{t} \mid \theta\right) \pi(\theta) \mathrm{d} \theta}
$$

em que $\pi\left(\theta \mid \tilde{y}_{t}\right)$ é distribuição a posteriori do vetor de parâmetros $\theta, \mathcal{L}\left(\tilde{y}_{t} \mid \theta\right)$ é função de verossimilhança para $\tilde{y}_{t}, \pi(\theta)$ é distribuição a priori dos parâmetros e $\int \mathcal{L}\left(\tilde{y}_{t} \mid \theta\right) \pi(\theta) \mathrm{d} \theta$ é verossimilhança marginal (CANTORE et al., 2013). Objetivos típicos de inferência (média ou moda da posteriori, por exemplo) envolvem o cálculo de

$$
\mathbb{E}[g(\theta)]=\int g(\theta) \pi\left(\theta \mid \tilde{y}_{t}\right) \mathrm{d} \theta
$$

em que $g(\theta)$ representa a função de interesse. No caso de um vetor de parâmetros, para encontramos alguma distribuição marginal precisamos resolver uma integral múltipla cuja 
solução geralmente não possui forma fechada. Assim, recorre-se à métodos de integração numérica (DEJONG; DAVE, 2011; CANTORE et al., 2013; MIAO, 2014). Quando não se sabe a forma das distribuições marginais, um dos métodos utilizados é o Monte Carlo em cadeias de Markov (Monte Carlo Markov chain - MCMC). Este método envolve a construção de uma cadeia de Markov em $\theta$ que convirja em distribuição para a posteriori de interesse (DEJONG; DAVE, 2011). O algoritmo original usado para realizar a integração numérica por meio de MCMC foi desenvolvido por Metropolis et al. (1953) e aprimorado por Hastings (1970). O random walk Metropolis-Hastings (RWMH), extensão do algoritmo Metropolis-Hastings, gera uma sequência de estimativas que segue um passeio aleatório e que formará a densidade a posteriori após descarte (burn-in) do início da sequência devido à instabilidade inicial. Para mais detalhes ver Canova (2007), DeJong e Dave (2011), Cantore et al. (2013) e Miao (2014).

\subsection{Monte Carlo: configuração}

O modelo RBC apresentado no capítulo 2 possui sete parâmetros estruturais, a saber, elasticidade do produto em relação ao capital $(\alpha)$, fator subjetivo de desconto $(\beta)$, coeficiente de aversão relativa ao risco $(\gamma)$, taxa de depreciação do capital $(\delta)$, peso do lazer na utilidade $(b)$, coeficiente autorregressivo do processo tecnológico $(\rho)$ e desvio-padrão do processo tecnológico $(\sigma)$. Nas estimações, os parâmetros $\alpha$ e $\delta$ serão fixados, isto é, serão substituídos pelos valores verdadeiros. Na prática, é comum que estes parâmetros sejam calibrados a partir dos dados. Logo, temos 5 parâmetros para estimar: $\theta=\{\beta, \gamma, b, \rho, \sigma\}$.

Para a simulação do modelo, consideramos os valores apresentados na Tabela B.1 (Apêndice) para os parâmetros. O coeficiente $b$ foi escolhido de modo que o valor de estado estacionário da proporção de horas trabalhadas seja aproximadamente $\frac{1}{3}$, tal como feito por Ruge-Murcia (2013). O coeficiente $\sigma$ foi definido de modo que as variáveis endógenas geradas ficassem em intervalos considerados "razoáveis" - o valor escolhido é o mesmo definido em Riscado (2012). Os valores definidos para os demais parâmetros, $\alpha, \beta, \gamma, \delta$ e $\rho$, são recorrentes na literatura.

Definimos quatro processos geradores de dados (data generating process - DGP) para estimar o modelo log-linearizado que assume que o choque de produtividade é normal. Os quatro processos considerados são:

- DGP I: modelo log-linearizado apresentado no capítulo 2 com choque de produtividade seguindo distribuição normal, ou seja, idêntico ao modelo será usado nas estimações;

- DGP II: modelo log-linearizado apresentado no capítulo 2, mas com choque de produtividade seguindo distribuição t de Student com 4 graus de liberdade - ou seja, admite mais eventos extremos;

- DGP III: modelo log-linearizado apresentado no capítulo 2, mas com choque de produtividade seguindo distribuição normal com contaminação única positiva de magnitude igual a 5 no meio da amostra (outlier centrado); 
- DGP IV: modelo log-linearizado apresentado no capítulo 2, mas com choque de produtividade seguindo distribuição normal com contaminação de múltiplos outliers cujas posições são sorteadas a partir de uma distribuição uniforme possibilitando até $5 \%$ de outliers positivos de magnitude igual a 3 e até $5 \%$ de outliers negativos de magnitude igual a -3 .

Note que em relação aos modelos gerados, $(i)$ o modelo estimado está corretamente especificado no caso do DGP I, (ii) possui má-especificação local no caso em que o DGP III é considerado visto que assintoticamente o efeito de um único outlier desaparece e, por fim, (iii) está globalmente mal especificado considerando-se o DGP II e o DGP IV uma vez que mudança de distribuição do choque tecnológico e contaminação deste por múltiplos outliers em proporção fixa da amostra não desaparecem assintoticamente.

Todos os procedimentos foram realizados empregando o software R. Para a simulação da versão log-linearizada do modelo foi utilizado o pacote $g E c o n$ versão 1.0.2. Este pacote utiliza o método proposto por Sims (2002) para obter a solução do modelo. Para as estimações foram utilizados os pacotes gmm versão 1.6-2, no caso de todos os estimadores baseados em momentos, e gEcon . estimation, no caso dos estimadores ML e BI. O pacote gmm, descrito em Chaussé (2010), computa tanto o GMM quanto os diferentes estimadores da classe GEL/GMC. Os resultados foram gerados a partir de 2.000 replicações de amostras com 200 observações, o que corresponde a 50 trimestres de dados, ou seja, um tamanho de amostra similar ao utilizado com dados efetivos. A inicialização de todos os estimadores foi feita usando os valores verdadeiros dos parâmetros de modo que as performances dos estimadores possam ser comparadas.

Nas estimações empregando métodos baseados em momentos consideramos tanto a versão sobreidentificada quanto a exatamente identificada. As condições de momento empregadas nestas estimações são apresentaras no Apêndice A. Para o caso exatamente identificado utilizamos as cinco primeiras condições de momento - equações (A.1), (A.2), (A.6), (A.7) e (A.8). Já no caso sobreidentificado, utilizamos todas as setes condições de momento - equações (A.1), (A.2), (A.6), (A.7), (A.8), (A.9) e (A.10). As prioris utilizadas na inferência bayesiana foram: $\beta \sim \operatorname{Beta}\left(0,98 ; 0,01^{2}\right), \gamma \sim \mathrm{N}\left(1,8 ; 0,5^{2}\right), b \sim \mathrm{N}\left(3,2 ; 1^{2}\right), \rho \sim \mathrm{N}\left(0,9 ; 0,05^{2}\right) \mathrm{e}$ $\sigma \sim \mathrm{IG}\left(0,007 ; 0,005^{2}\right)$. Foram colocados limites inferior e superior nos algoritmos de implementação de todos os estimadores (incluindo BI) de acordo com as restrições do modelo, ou seja, $0<\beta<1, \gamma>0, b>0,-1<\rho<1$ e $\sigma>0$. 


\section{Resultados}

As tabelas e figuras que sumarizam os resultados deste trabalho estão no Apêndice B. Na média das replicações, as condições de momento utilizadas nas estimações por meio dos métodos baseados em momentos apresentaram média zero no tempo, inclusive as três condições de momento "artificiais" geradas a partir de condições de momento "originais" (Tabela B.2). A Tabela B.3 apresenta as matrizes de correlação das condições de momento dos casos analisados. Trata-se da média das correlações entre as condições de momento geradas a partir das séries simuladas em cada DGP e dos parâmetros verdadeiros. Nota-se que a correlação par-a-par é consideravelmente alta mesmo entre condições de momento "originais" - caso das condições $g_{1}\left(x_{t}, \theta\right)$ e $g_{3}\left(x_{t}, \theta\right)$, por exemplo. Além deste caso, a correlação é superior a $50 \%$ entre $g_{1}\left(x_{t}, \theta\right)$ e $g_{7}\left(x_{t}, \theta\right)$ e entre $g_{2}\left(x_{t}, \theta\right)$ e $g_{6}\left(x_{t}, \theta\right)$, em todos os DGPs. Apesar disso, as condições parecem ter sido informativas o suficiente para identificar os parâmetros para a maior parte dos estimadores. Cabe destacar que uma das dificuldades decorrentes do uso de condições de momento "artificiais" é a possibilidade de surgimento de singularidade estocástica entre condições de momento, o que teria sérias implicações em termos de implementação computacional.

Os resultados das estimativas em cada experimento estão sumarizados nas Tabelas B.5 a B.9 e nas Figuras B.1 a B.5. Para facilitar a exposição, cada parâmetro estimado aparece em uma tabela e em uma figura separadamente distinguindo-se qual DGP gerou os dados considerados em cada estimação. As Tabelas, dividas nos casos exatamente e sobreidentificado (para os métodos baseados em momentos), exibem: ( $i$ ) média das estimativas, (ii) mediana das estimativas, (iii) viés, dado pela diferença entre a média e o valor verdadeiro do parâmetro, (iv) erro quadrático médio (EQM) e (v) erro absoluto médio (EAM). As Figuras mostram as distribuições dos parâmetros gerados por cada estimador considerando as 2.000 replicações do experimento. Por questão de espaço, as distribuições geradas nos casos sobreidentificado e exatamente identificado dos métodos baseados em momentos foram sobrepostas (linhas pretas contínuas e cinzas pontilhadas, respectivamente). No caso das estimações usando BI, o RWMHMCMC contou com cadeia de tamanho 5.500 (com 1.500 de burn-in) e rotina de maximização csminwel. Aumentos do tamanho da cadeia não levaram a melhora dos resultados, a não ser nos casos de valores muito grandes, o que comprometeria bastante o experimento devido ao grande tempo consumido pela metodologia, uma das suas desvantagens. No GMM e nos métodos pertencentes à família GEL/GMC utilizamos o método de otimização n lminb.

De modo geral, as estimativas dos métodos baseados em momentos nos casos sobreidentificado e exatamente identificado foram bastante similares, com exceção do GMM que no caso exatamente identificado obteve bom desempenho (exceto na estimação do parâmetro $\rho$ ) e no caso sobreidentificado não se saiu bem na estimação dos parâmetros $\gamma, b$ e $\rho$. Em relação aos testes de especificação, mostrados na Tabela B.4, nota-se que enquanto o teste $\mathrm{J}$ rejeitou ao nível de significância de $5 \%$ entre $26,40 \%$ e $33,45 \%$ das especificações no caso do GMM, o 
mesmo teste rejeitou quase a totalidade das especificações no caso dos estimadores da família GEL/GMC. Para estes últimos, os testes LM e LR de especificação rejeitaram ao mesmo nível de significância entre $63,25 \%$ e 69,80\% e entre $75,25 \%$ e 79,80\% das especificações, respectivamente. Verifica-se que mesmo no caso do modelo estimado com especificação correta, os testes apontaram rejeição da especificação. Além disso, a proporção de rejeições nos casos de especificação incorreta (DGP II, DGP III e DGP IV) em geral não foi superior à proporção de rejeições do caso corretamente especificado (DGP I), como era esperado. Deve-se ressaltar que os dados foram gerados a partir da solução log-linearizada do modelo e, com isso, o uso de condições de momento oriundas das condições de primeira ordem do modelo na estimação pode gerar um problema de especificação que pode ter influenciado os resultados dos destes.

As versões com e sem suavização das condições de momento dos estimadores GEL/GMC apresentaram desempenhos muito semelhantes e não é possível fazer distinção clara entre elas. $\mathrm{Na}$ sequência deste texto, em vários momentos mencionaremos ambas as versões simultaneamente ao indicar com um $\mathrm{S}$ entre parênteses antes do nome do estimador a possibilidade de usar a versão suavizada. Outro destaque geral foi a ocorrência de estimativas extremas ou bastante destoantes dos valores verdadeiros no caso dos estimadores ETEL, ETHD e suas versões suavizadas (Figuras B.1 a B.5). Isto acabou comprometendo média, EQM e EAM destes estimadores, mas não a mediana uma vez que esta é mais robusta a presença destes valores atípicos (Tabelas B.5 a B.9). Cabe notar que este comportamento esteve presente na estimação de todos os parâmetros, apesar de se apresentar de maneiras distintas: estimativas no limite do espaço paramétrico (parâmetro $\beta$ ), estimativas muito destoantes dos valores verdadeiros $(\gamma$ e $\sigma)$ e ambos os problemas ( $b$ e $\rho$ ). A obtenção de estimativas destoantes dos valores verdadeiros evidencia um problema de performance dos estimadores em questão, o que não pôde ser superado com a utilização de outros métodos de otimização disponíveis no pacote gmm.

Os parâmetros $\beta$, $\gamma$ e $b$ foram aqueles para os quais os estimadores analisados neste trabalho retornaram as estimativas mais próximas dos valores verdadeiros, com exceção $(i)$ dos estimadores ETEL, ETHD e suas versões suavizadas, pelo motivo destacado no parágrafo anterior, (ii) do GMM que, mesmo considerando a mediana, obteve desempenho muito ruim em relação aos parâmetros $\gamma$ e $b$ no caso sobreidentificado e, por último, (iii) do ML no caso do parâmetro $\gamma$. As Figuras B.2 e B.3 mostram que ambas as distribuições de $\gamma$ e $b$ geradas pelo GMM no caso sobreidentificado foram assimétricas à direita e bastante espaçadas, corroborando o desempenho ruim refletido nas estatísticas contidas nas Tabelas B.6 e B.7. A performance do GMM na estimação dos parâmetros $\rho$ e $\sigma$ não foi muito boa tanto no caso exatamente identificado quanto no caso sobreidentificado.

No geral, os parâmetros $\rho$ e $\sigma$ foram os mais difíceis de serem estimados, cabendo destacar a boa performance do estimador (S)EL para obter estimativas precisas para ambos. No caso do $\rho$, o problema com os demais estimadores parece ter decorrido da proximidade do valor verdadeiro $(0,9)$ de 1 , número que define o limite superior do espaço paramétrico atribuído a este parâmetro. Boa parte das estimativas de $\sigma$ foram viesadas para baixo, tornando-se cada vez mais próximas 
do valor verdadeiro nos casos de má-especificação, algo esperado devido a inclusão de valores extremos levar a aumento da variabilidade dos dados. Com isso, este resultado deve ser tratado como uma coincidência e não sinal de robustez dos estimadores considerados.

Especificamente em relação ao parâmetro $\beta$, os diferentes experimentos geraram resultados semelhantes e a adição de desvios da distribuição normal (do choque de produtividade) levou basicamente a aumentos de EQM e EAM dos estimadores, mais notadamente no caso da distribuição t e da inclusão de múltiplos outliers e menos no de inclusão de um único outlier (Tabela B.5). $\mathrm{Na}$ comparação entre os diferentes estimadores, os menores EQMs foram registrados por BI, GMM, (S)CUE e (S)EL, enquanto os menores EAMs foram de BI e (S)EL. O problema com os estimadores (S)ETEL e (S)ETHD decorreu da existência de considerável massa de probabilidade perto de zero, limite inferior do espaço paramétrico, como pode ser observado na Figura B.1. Outro destaque em relação às estimavas para $\beta$ foi que, mesmo no caso de especificação correta (DGP I), o estimador ML apresentou desempenho inferior ao dos estimadores GMM, GEL/GMC destacados e BI. Isso decorreu da concentração de estimativas ao redor de 0,9 , o que pode estar associado, por exemplo, a existência de um máximo local na função objetivo do estimador em questão.

A estimação do parâmetro $\gamma$ costuma ser a mais difícil, como apontado por Riscado (2012) e Ruge-Murcia (2013). Isto decorre do fato de ele ser a principal fonte de não-linearidade do modelo uma vez que representa a curvatura da função utilidade. Para este parâmetro, temos que ML e GMM no caso sobreidentificado apresentaram os piores desempenhos em termos de viés, EQM e EAM (Tabela B.2). Já o GMM no caso exatamente identificado apresentou boa performance em razão de EQM e EAM baixos. Os estimadores (S)EL, (S)CUE e (S)ET entregaram os melhores resultados em termos de viés, EQM e EAM, enquanto (S)ETEL e (S)ETHD ficaram entre os piores. As estimativas dos últimos apresentaram concentração ao redor do valor verdadeiro $(1,8)$ e ao redor de 0,75 . Devido a um problema semelhante, o ML entregou maiores viés, EQM e EAM; desta vez por apresentar concentração bastante espaçada ao redor de 1,8 e em torno de 30 - número bastante distante do verdadeiro. O espaçamento ao redor do verdadeiro, assim como a concentração ao redor de 30 , aumentou consideravelmente com a inclusão de erros de especificação (Figura B.2).

Os estimadores (S)EL e ML foram os que obtiveram as melhores performances na estimação do parâmetro $b$ em todos os desenhos considerados. Nota-se uma clara melhora do estimador (S)EL ao ir do caso exatamente identificado para o sobreidentificado, o que não ocorreu com o estimador (S)CUE, cujo desempenho acabou piorando, mas não o suficiente para ele sair da lista de estimadores com melhores resultados para o parâmetro em questão (Tabela B.7). Além destes três, o GMM no caso exatamente identificado também gerou estimativas razoáveis comparativamente aos demais, principalmente no casos em que os dados utilizados foram do DGP I, do DGP III e do DGP II, nesta ordem. Mesmo com o emprego de priori informativa, o estimador BI entregou estimativas ruins para o parâmetro $b$ na comparação com às do ML em termos de viés, EQM e EAM, ficando em posição intermediária na classificação de desempenho 
considerando todos os estimadores. O GMM no caso sobreidentificado entregou notadamente os priores resultados e os estimadores (S)ETEL e (S)ETHD tiveram seus resultados comprometidos devido a estimativas atípicas, isto é, distantes do valor verdadeiro do parâmetro (Figura B.3).

Os resultados associados ao parâmetro $\rho$ apresentam as maiores peculiaridades pelo fato de quase todos os estimadores entregarem estimativas concentradas em dois pontos: 0,9 (valor verdadeiro) e 1, como pode ser observado na Figura B.4. Os estimadores que apresentaram este comportamento foram ET, CUE, ETEL, HD, ETHD e suas versões suavizadas, ou seja, dez dos quinze estimadores analisados neste trabalho. Apesar de não apresentar este comportamento, o GMM contou com o maior viés no caso sobreidentificado e um dos maiores no caso exatamente identificado, com média e mediana próximos a 1 em ambos os casos. O grande destaque positivo de performance foi dos estimadores EL e SEL que entregaram estimativas concentradas apenas ao redor do valor verdadeiro, além de possuírem os menores EQMs e EAMs entre todos os estimadores considerados (Tabela B.8). ML apesar de reportar valores próximos do verdadeiro, gerou uma distribuição bastante espaçada ao redor deste valor. O estimador BI, por sua vez, apesar de entregar EQM semelhante ao do (S)EL, acabou retornando estimativas mais viesadas que as do estimador ML e EAM pelo menos duas vezes superior ao do (S)EL, em todos os casos analisados, mesmo contando com priori informativa para o parâmetro em questão.

Para o parâmetro $\sigma$ impomos restrição de positividade no espaço paramétrico uma vez que ele entra nas condições de momento na forma quadrática. Isto tende a explicar o porque de no caso dos estimadores (S)ET, (S)CUE, (S)HD, (S)ETEL, (S)ETHD e, em menor medida, no GMM (caso exatamente identificado), terem aparecido estimativas perto de zero (Figura B.5). De certa forma, o algoritmo de maximização poderia estar buscando o outro valor admitido $(-0,007)$ e foi impedido de alcançá-lo devido ao limite inferior imposto. Isto demonstra uma das dificuldades associadas a estimação do parâmetro que mensura a variabilidade do choque de produtividade do modelo. Vários estimadores da classe GEL/GMC acabaram entregando resultados atípicos devido a estimativas muito superiores ao valor verdadeiro em algumas das replicações. O estimador ML apresentou uma peculiaridade na estimação deste parâmetro: a distribuição dos resultados concentrou-se ao redor de 0,006 e de 0,01, na estimação usando os dados gerados no DGP I, e ao redor de 0,008 e 0,013, no caso do DGP IV. No caso corretamente especificado (DGP I) e no caso de contaminação por apenas um outlier centrado na amostra (DGP III), o estimador BI foi o que entregou os melhores resultados em termos de viés, EQM e EAM, seguido de perto pelo estimador (S)EL (Tabela B.9). Já nos casos de estimação com especificação incorreta usando dados do DGP II e do DGP IV, o estimador (S)EL tendeu a superar o desempenho do BI, tanto em termos de viés, EQM e EAM. Com isso, considerando a existência de um parâmetro fixo, o (S)EL pode ser considerado mais robusto que o BI na estimação de $\sigma$, visto que ele conseguiu entregar estimativas mais precisas e com EQM e EAM menores.

Nota-se, em geral, que o estimador (S)EL, tanto no caso exatamente identificado quanto no sobreidentificado, e o estimador BI foram os que obtiveram os melhores desempenhos em termos 
de viés, EQM e EAM, nas situações em que o modelo estimado está ou não com problemas de especificação. A boa performance do estimador EL na situação de modelo corretamente especificado era esperada uma vez que este possui boas propriedades assintóticas nesta situação. Já o estimador BI, por incorporar a visão do pesquisador anterior à estimação, entrega bons resultados, principalmente quando a configuração da distribuição a priori é boa - o que foi o caso visto que tanto a priori quanto as inicializações de todos os estimadores foram definidos a partir dos valores verdadeiros dos parâmetros visando a comparação justa dos estimadores. Além de (S)EL e BI, cabe destacar a performance dos estimadores (S)CUE, (S)HD e (S)ET que, apesar do desempenho comparativo intermediário, se mostraram boas ferramentas.

Os estimadores GMM, principalmente no caso sobreidentificado, e ML apresentaram desempenhos consideravelmente abaixo de boa parte de seus concorrentes devido a entrega de estimativas imprecisas. Como no caso sobreidentificado do GMM as condições de momento não necessariamente zeram, temos que o fato deste estimador ser de forma quadrática tende a comprometer o seu desempenho quando os dados são expostos a perturbações. Neste sentido, estimadores da classe GEL/GMC possuem a vantagem de sempre satisfazerem as restrições devido a ponderação feita por probabilidade implícita que visa diretamente as observações e não nas condições de momento, como acontece no GMM. Já o estimador ML acabou registrando estimativas concentradas em pontos diferentes dos valores verdadeiros dos parâmetros em vários casos, algo que pode estar associado a presença de máximos locais na função objetivo deste estimador.

O desempenho de estimadores baseados em ET e HD (ETEL, ETHD e suas versão suavizadas), foi bastante comprometido por estimativas atípicas em algumas das replicações dos experimentos. Esperava-se que estes estimadores conseguissem entregar bons resultados principalmente ao comparar as performances dos diferentes estimadores sob problemas de especificação - principalmente no caso do estimador ETHD que apresenta boas propriedades teóricas tanto nos casos em que o modelo estimado está bem especificado, quanto nos casos em que este possui problemas de especificação de ordens global e local. Entretanto, cabe ressaltar que outros estudos que considerem outras fontes de má-especificação devem ser realizados. Além disso, outras análises que considerem diferentes inicializações podem ser feitas visando analisar o desempenho destes estimadores em outras situações - podendo ser analisado com mais detalhes a escolha dos métodos de otimização utilizados na implementação dos estimadores, algo fora do escopo deste trabalho.

Uma das dificuldades relacionadas ao uso de métodos baseados em momentos, tal como destacado por Riscado (2012), é obter um número de condições de momento suficiente para a estimação de modelos DSGE que possuam muitos parâmetros. Recorrer a definição de condições de momento "artificiais" pode gerar problemas no momento da estimação de modo a tornar difícil o emprego destes métodos. Outra limitação dos métodos baseados em momentos é a impossibilidade de considerar variáveis latentes tal como feito na representação em espaço de estados utilizada pelos estimadores ML e BI. No entanto, se possível, alguns destes esti- 
madores podem ser utilizados visando a obtenção de bons resultados mesmo em situações de má-especificação, tal como encontrado neste trabalho. Em relação à inferência bayesiana, apesar das vantagens do uso de informações a priori já mencionadas em Ruge-Murcia (2007), cabe destacar que se os dados não forem informativos o suficiente a distribuição a posteriori poderá ser amplamente dominada pela configuração da priori. Deste modo, testes de sensibilidade envolvendo a distribuição a priori são fundamentais para garantir a robustez dos resultados no sentido definido neste trabalho e considerando a existência de um parâmetro verdadeiro (fixo), tal como considerado na inferência frequentista. Além disso, outra desvantagem do BI é o tempo necessário para obtenção da distribuição a posteriori que costuma ser consideravelmente alto. 


\section{Conclusão}

Para avaliar o desempenho de diferentes estimadores baseados em momentos das famílias verossimilhança empírica generalizada (GEL) e mínimo contraste generalizado (GMC) na estimação de modelos DSGE, nós realizamos uma análise de Monte Carlo considerando diferentes processos geradores de dados de modo a verificar os resultados das estimações sob especificação correta e incorreta do modelo considerado na estimação. Como benchmark consideramos os estimadores método dos momentos generalizado (GMM), máxima verossimilhança (ML) e inferência bayesiana (BI). Utilizamos um modelo de ciclos reais de negócios (RBC), núcleo dos modelos DSGE atuais, que possui dificuldades similares e poucos parâmetros, o que contribui para a análise dos resultados. A análise baseou-se na comparação de média, mediana, viés, erro quadrático médio (EQM) e erro absoluto médio (EAM), além da observação das distribuições dos parâmetros geradas por cada estimador. No experimento em que a especificação é correta, os choques de produtividade da economia seguem uma distribuição normal. Nos experimentos que consideraram problemas de especificação, o modelo estimado considera que os choques de produtividade seguem uma distribuição normal enquanto os dados foram gerados considerandose que estes choques seguem uma distribuição $t$ de Student e uma distribuição normal com a inclusão de um único outlier positivo centrado e de múltiplos outliers (positivos e negativos).

Os principais resultados encontrados foram: $(i)$ o estimador de verossimilhança empírica (EL) e sua versão com condições de momento suavizadas (SEL), tanto no caso exatamente identificado quanto no sobreidentificado, e a inferência bayesiana (BI) foram os que obtiveram, nesta ordem, os melhores desempenhos em termos de viés, EQM e EAM, nas situações em que o modelo estimado está ou não com problemas de especificação; (ii) além de (S)EL e BI, os estimadores continuous updating empirical likelihood (CUE), minimum Hellinger distance (HD), exponential tilting (ET) e suas versões suavizadas apresentaram desempenho comparativo intermediário, se mostrando boas ferramentas para a estimação do modelo analisado; (iii) o desempenho dos estimadores exponentially tilted empirical likelihood (ETEL), exponential tilting Hellinger distance (ETHD) e suas versões suavizadas, foi bastante comprometido por estimativas atípicas (destoantes do valor verdadeiro) em algumas das replicações dos experimentos; (iv) as versões com e sem suavização das condições de momento dos estimadores das famílias GEL/GMC apresentaram desempenhos muito semelhantes de modo a não ser possível fazer distinção entre elas; ( $v$ ) os estimadores GMM, principalmente no caso sobreidentificado, e ML apresentaram desempenhos consideravelmente abaixo de boa parte de seus concorrentes devido a entrega de estimativas imprecisas.

De forma geral, o desempenho de alguns dos estimadores GEL/GMC, mais especificamente EL e sua versão com condições de momento suavizadas, foi similar (e em alguns casos até superior) ao estimador bayesiano e superior ao desempenho de GMM e ML. Destacamos que a entrega de estimativas tão boas quanto as do método bayesiano é um resultado de destaque 
devido a vantagem que o último possui por incorporar informações prévias. Entretanto, algumas dificuldades associadas à definição das condições de momento informativas o bastante e em quantidade suficiente para a identificação dos parâmetros do modelo podem inviabilizar a utilização dos estimadores GEL/GMC (e também do GMM). O fato das restrições sempre serem zeradas nos estimadores GEL/GMC faz com que estes apresentem vantagem considerável em relação ao GMM nos casos de sistema sobreidentificado (mais condições de momento do que parâmetros a serem estimados). A inferência bayesiana, por sua vez, também possui dificuldades tais como priori dominando o resultado final (dados pouco informativos) e tempo de estimação consideravelmente maior. Deste modo, os estimadores GEL/GMC analisados neste trabalho podem ser boas ferramentas para a estimação de modelos DSGE dadas a suas boas características no contexto de má-especificação, algo bastante presente neste tipo de modelo, e pelo fato deles serem de fácil implementação computacional e entregar resultados mais rapidamente. 


\section{Referências}

ANATOLYEV, S. GMM, GEL, serial correlation, and asymptotic bias. Econometrica, v. 73, n. 3, p. 983-1002, 2005.

ANATOLYEV, S.; GOSPODINOV, N. Methods for estimation and inference in modern econometrics. Boca Raton: CRC Press, 2011.

ANDREWS, D. W. K. Heteroskedasticity and autocorrelation consistent covariance matrix estimation. Econometrica, v. 59, n. 3, p. 817-858, 1991.

ANTOINE, B.; DOVONOV, P. Robust estimation with Exponentially Tilted Hellinger Distance. Simon Fraser University, Department of Economics, Working Paper n. 15. 2017.

BERAN, R. Minimum Hellinger distance estimates for parametric models. The Annals of Statistics, v. 5, n. 3, p. 445-463, 1977.

BICKEL, P.; KLAASSEN, C.; RITOV, Y.; WELLNER, J. Efficient and adaptive estimation for Semiparametric models. Baltimore: Johns Hopkins Press, 1993.

BLANCHARD, O. J.; KHAN, C. The solution of linear difference models under rational expectations. Econometrica, v. 48, n. 5, p. 1305-1311, 1980.

BORWEIN, J. M.; LEWIS, A. S. Duality relationships for entropy-like minimization problems. SIAM Journal on Control and Optimization, v. 29, n. 2, p. 325-338, 1991.

BRAUN, R. A. Tax disturbances and real economic activity in the postwar United States. Journal of Monetary Economics, v. 33, n. 3, p. 441-462, 1994.

BURNSIDE, C.; EICHENBAUM, M.; REBELO, S. Labor hoarding and the business cycle. The Journal of Political Economy, v. 101, n. 2, p. 245-273, 1993.

CANOVA, F. Methods for applied macroeconomic research. [S.1.]: Princeton University Press, 2007. v. 13.

CANTORE, C.; GABRIEL, V. J.; LEVINE, P.; PEARLMAN, J.; YANG, B. The science and art of DSGE modelling: I - construction and Bayesian estimation. In: HASHIMZADE, N.; THORNTON, M. A. Handbook of research methods and applications in empirical macroeconomics. Northampton: Edward Elgar Publishing, 2013. p. 411-440.

CHAUSSÉ, P. Computing generalized method of moments and generalized empirical likelihood with R. Journal of Statistical Software, v. 34, n. 11, p. 1-35, 2010.

CHRISTIANO, L. J.; EICHENBAUM, M. Current real-business-cycle theories and aggregate labor-market fluctuations. The American Economic Review, v. 82, n. 3, p. 430-450, 1992.

CORCORAN, S. A. Bartlett adjustment of empirical discrepancy statistics. Biometrika, v. 85, n. 4, p. 967-972, 1998.

CRESSIE, N.; READ, T. R. C. Multinomial goodness-of-fit tests. Journal of the Royal Statistical Society, Series B (Methodological), v. 46, n. 3, p. 440-464, 1984. 
DEJONG, D. N.; DAVE, C. Structural macroeconometrics. [S.1.]: Princeton University Press, 2011.

FERNANDEZ-VILLAVERDE, J. The econometrics of DSGE models. NBER Working Paper Series n. 15. 2009.

HAMILTON, J. D. Time Series Analysis. Princeton, New Jersey: Princeton University Press, 1994.

HANSEN, G. D. Indivisible labor and the business cycle. Journal of Monetary Economics, v. 16, n. 3, p. 309-327, 1985.

HANSEN, L. P. Large sample properties of generalized method of moments estimators. Econometrica, v. 50, n. 4, p. 1029-1054, 1982.

HANSEN, L. P.; HEATON, J.; YARON, A. Finite-sample properties of some alternative GMM estimators. Journal of Business \& Economic Statistics, v. 14, n. 3, p. 262-280, 1996.

HANSEN, L. P.; SINGLETON, K. J. Generalized instrumental variables estimation of nonlinear rational expectations models. Econometrica, v. 50, n. 5, p. 1269-1286, 1982.

HASTINGS, W. K. Monte Carlo sampling methods using Markov chains and their applications. Biometrika, v. 57, n. 1, p. 97-109, 1970.

HUBER, P. J.; RONCHETTI, E. M. Robust statistics. Hoboken, New Jersey: WILEY, 2009.

IMBENS, G.; JOHNSON, P.; SPADY, R. Information theoretic approaches to inference in moment condition models. Econometrica, v. 66, n. 2, p. 333-357, 1998.

IMBENS, G. W. One-step estimators for over-identified generalized method of moments models. The Review of Economic Studies, v. 64, n. 3, p. 359-383, 1997.

KITAMURA, Y. Empirical likelihood methods in econometrics: Theory and practice. Manuscrito não publicado. 2006.

KITAMURA, Y.; OTSU, T.; EVDOKIMOV, K. Robustness, infinitesimal neighborhoods, and moment restrictions. Econometrica, v. 81, n. 3, p. 1185-1201, 2013.

KITAMURA, Y.; STUTZER, M. An information-theoretic alternative to generalized method of moments estimation. Econometrica, v. 65, n. 4, p. 861-874, 1997.

LAURINI, M. P.; HOTTA, L. K. Generalized moment estimation of stochastic differential equations. Computational Statistics, v. 31, n. 3, p. 1169-1202, 2015.

MAASOUMI, E. How to live with misspecification if you must. Journal of Econometrics, v. 44, n. 2, p. 67-86, 1990.

MCCANDLESS, G. The ABCs of RBCs: An introduction to dynamic macroeconomic models. Cambridge, Massachusetts and London: Harvard University Press, 2008.

METROPOLIS, N.; ROSENBLUTH, A. W.; ROSENBLUTH, M. N.; TELLER, A. H.; TELLER, E. Equation of state calculations by fast computing machines. The Journal of Chemical Physics, v. 21, n. 6, p. 1087-1092, 1953.

MIAO, J. Economic dynamics in discrete time. Cambridge, Massachusetts: MIT Press, 2014. 
NEWEY, W. K.; SMITH, R. J. Higher order properties of GMM and generalized empirical likelihood estimators. Econometrica, v. 72, n. 1, p. 219-255, 2004.

NEWEY, W. K.; WEST, K. D. Hypothesis testing with efficient method of moments estimation. International Economic Review, v. 28, n. 3, p. 777-787, 1987.

OWEN, A. Empirical likelihood for linear models. The Annals of Statistics, v. 17, n. 4, p. 1725-1747, 1991.

OWEN, A. B. Empirical likelihood ratio confidence intervals for a single functional. Biometrika, v. 75, n. 2, p. 237-249, 1988.

QIN, J.; LAWLESS, J. Empirical likelihood and general estimating equations. The Annals of Statistics, v. 22, n. 1, p. 300-325, 1994.

RISCADO, S. On the estimation of dynamic stochastic general equilibrium models: an empirical likelihood approach. In: BALKE, N.; CANOVA, F.; MILANI, F.; WYNNE, M. A. DSGE Models in Macroeconomics: Estimation, evaluation, and new developments - advances in econometrics (volume 28). Bingley: Emerald Group Publishing, 2012. p. 387-419.

RUGE-MURCIA, F. J. Methods to estimate dynamic stochastic general equilibrium models. Journal of Economic Dynamics and Control, v. 31, n. 8, p. 2599-2636, 2007.

RUGE-MURCIA, F. J. Generalized method of moments estimation of DSGE models. In: HASHIMZADE, N.; THORNTON, M. A. Handbook of research methods and applications in empirical macroeconomics. Northampton: Edward Elgar Publishing, 2013. p. 464-485.

SARGENT, T. J. Two models of measurements and the investment accelerator. The Journal of Political Economy, v. 97, n. 2, p. 251-287, 1989.

SCHENNACH, S. M. Point estimation with exponentially tilted empirical likelihood. The Annals of Statistics, v. 35, n. 2, p. 634-672, 2007.

SIMS, C. A. Solving linear rational expectations models. Computational economics, Springer, v. 20, n. 1, p. 1-20, 2002.

SMITH, R. J. Alternative semi-parametric likelihood approaches to generalised method of moments estimation. The Economic Journal, v. 107, p. 503-519, 1997.

SMITH, R. J. GEL criteria for moment condition models. Econometric Theory, v. 27, n. 6, p. 1192-1235, 2011.

UHLIG, H. A toolkit for analysing nonlinear stochastic models easily. In: MARIMON, R.; SCOTT, A. Computational Methods for Study of Dynamic Economies. Oxford: Oxford University Press, 1999. p. 30-61.

WOLFOWITZ, J. The minimum distance method. The Annals of Mathematical Statistics, v. 28, n. 1, p. $78-88,1957$. 



\section{APÊNDICE A - Condições de momento}

A partir das CPOs (2.5) e (2.6) derivamos as duas primeiras condições de momento que serão empregadas na estimação do modelo dados por

$$
\begin{gathered}
g_{1}\left(x_{t}, \theta\right) \equiv b-w_{t} c_{t}^{-\gamma} \\
g_{2}\left(x_{t}, \theta\right) \equiv \beta\left(1-\delta+r_{t+1}\right)\left(\frac{c_{t+1}}{c_{t}}\right)^{-\gamma}-1
\end{gathered}
$$

Como podemos identificar o parâmetro $\delta$ usando lei de movimento do capital - equação (2.3) -, esta equação não é usada como condição de momento e poderia ser usada na calibração do parâmetro em questão.

Aplicando o operador esperança na equação (2.2) do nível de tecnologia obtemos

$$
\mathbb{E}\left[\ln z_{t}-\rho \ln z_{t-1}\right]=0
$$

e usando o fato que $\varepsilon_{z, t} \sim\left(0, \sigma^{2}\right)$, sabemos que

$$
\mathbb{E}\left[\left(\ln z_{t}-\rho \ln z_{t-1}\right)^{2}-\sigma^{2}\right]=0 .
$$

Apesar de $z_{t}$ ser uma variável não observável, podemos usar a função de produção definida em (2.1) para colocarmos o nível tecnológico em função do produto $y_{t}$, do estoque de capital $k_{t}$ e da proporção de horas trabalhadas $n_{t}$ :

$$
y_{t}=z_{t} k_{t}^{\alpha} n_{t}^{1-\alpha} \Rightarrow z_{t}=y_{t} k_{t}^{-\alpha} n_{t}^{-(1-\alpha)} \Rightarrow \ln z_{t}=\ln y_{t}-\alpha \ln k_{t}-(1-\alpha) \ln n_{t}
$$

Então, combinando (A.3) e (A.4) com o resultado (A.5) definimos mais duas condições dados por

$$
\begin{gathered}
g_{3}\left(x_{t}, \theta\right) \equiv \ln y_{t}-\rho \ln y_{t-1}-\alpha\left(\ln k_{t}-\rho \ln k_{t-1}\right)-(1-\alpha)\left(\ln n_{t}-\rho \ln n_{t-1}\right) \\
g_{4}\left(x_{t}, \theta\right) \equiv\left[\ln y_{t}-\rho \ln y_{t-1}-\alpha\left(\ln k_{t}-\rho \ln k_{t-1}\right)-(1-\alpha)\left(\ln n_{t}-\rho \ln n_{t-1}\right)\right]^{2}-\sigma^{2}
\end{gathered}
$$

Como o parâmetro $\alpha$ é calibrado, as condições de momento (A.6) e (A.7) identificam os parâmetros $\rho$ e $\sigma$. Entretanto, com as quatro condições de momento geradas a partir de equações do modelo ainda não somos capazes de identificar os parâmetros $\beta, \gamma$ e $b$. Com isso, precisaremos recorrer a definição de condições de momento "artificiais" tal como feito por Riscado (2012). Utilizando as condições de momento "originais" (A.1) e (A.2) podemos escrever as três condições de momento "artificiais" seguintes:

$$
\begin{gathered}
g_{5}\left(x_{t}, \theta\right) \equiv\left(g_{1}\left(x_{t}, \theta\right)\right)^{2} \odot\left(g_{2}\left(x_{t}, \theta\right)\right)^{2} \\
g_{6}\left(x_{t}, \theta\right) \equiv\left(g_{1}\left(x_{t}, \theta\right)\right)^{2} \odot g_{2}\left(x_{t}, \theta\right) \\
g_{7}\left(x_{t}, \theta\right) \equiv\left(g_{2}\left(x_{t}, \theta\right)\right)^{2} \odot g_{1}\left(x_{t}, \theta\right)
\end{gathered}
$$

em que $\odot$ é o produto de Hadamard. 



\section{APÊNDICE B - Tabelas e Figuras}

Tabela B.1 - Parâmetros verdadeiros

\begin{tabular}{ccccccccc}
\hline & \multicolumn{3}{c}{ Calibrado } & \multicolumn{6}{c}{ A ser estimado } \\
\hline Parâmetro & $\alpha$ & $\delta$ & $\beta$ & $\gamma$ & $b$ & $\rho$ & $\sigma$ \\
\hline Valor & 0,33 & 0,025 & 0,98 & 1,8 & 3,2 & 0,9 & 0,007 \\
\hline
\end{tabular}

Tabela B.2 - Médias das condições de momento

\begin{tabular}{ccccc}
\hline & DGP I & DGP II & DGP III & DGP IV \\
\hline g1 & $-0,000577$ & $-0,001803$ & 0,008796 & $-0,003939$ \\
g2 & $-0,000180$ & $-0,000276$ & $-0,002179$ & 0,000107 \\
g3 & 0,000072 & 0,000107 & 0,000567 & $-0,000001$ \\
g4 & $-0,000018$ & 0,000016 & $-0,000014$ & 0,000013 \\
g5 & 0,000002 & 0,000011 & 0,000003 & 0,000009 \\
g6 & 0,000001 & 0,000006 & $-0,000014$ & 0,000012 \\
g7 & 0,000000 & $-0,000000$ & 0,000009 & $-0,000004$ \\
\hline
\end{tabular}

Nota: média das condições de momento geradas a partir dos dados de cada DGP em cada replicação considerando o valor verdadeiro dos parâmetros. 
Tabela B.3 - Correlação entre as condições de momento

\begin{tabular}{|c|c|c|c|c|c|c|c|}
\hline & $g_{1}$ & $g_{2}$ & $g_{3}$ & $g_{4}$ & $g_{5}$ & $g_{6}$ & $g_{7}$ \\
\hline \multicolumn{8}{|c|}{ DGP I: distribuição normal } \\
\hline$g_{1}$ & 1,0000 & & & & & & \\
\hline$g_{2}$ & $-0,1244$ & 1,0000 & & & & & \\
\hline$g_{3}$ & 0,6197 & $-0,0355$ & 1,0000 & & & & \\
\hline$g_{4}$ & 0,0346 & $-0,1543$ & 0,0717 & 1,0000 & & & \\
\hline$g_{5}$ & $-0,0055$ & $-0,0180$ & 0,0205 & 0,1859 & 1,0000 & & \\
\hline$g_{6}$ & $-0,2333$ & 0,6505 & $-0,1311$ & $-0,1252$ & $-0,0166$ & 1,0000 & \\
\hline$g_{7}$ & 0,5734 & $-0,2909$ & 0,3468 & 0,0810 & 0,0070 & $-0,3548$ & 1,0000 \\
\hline \multicolumn{8}{|c|}{ DGP II: distribuição t } \\
\hline$g_{1}$ & 1,0000 & & & & & & \\
\hline$g_{2}$ & $-0,1214$ & 1,0000 & & & & & \\
\hline$g_{3}$ & 0,6062 & $-0,0351$ & 1,0000 & & & & \\
\hline$g_{4}$ & 0,0146 & $-0,2063$ & 0,1296 & 1,0000 & & & \\
\hline$g_{5}$ & $-0,0314$ & $-0,0165$ & 0,0124 & 0,2505 & 1,0000 & & \\
\hline$g_{6}$ & $-0,2044$ & 0,6579 & $-0,1067$ & $-0,1697$ & $-0,0193$ & 1,0000 & \\
\hline$g_{7}$ & 0,5727 & $-0,2031$ & 0,3401 & 0,0321 & $-0,0375$ & $-0,2268$ & 1,0000 \\
\hline \multicolumn{8}{|c|}{ DGP III: distribuição normal com outlier fixo centrado } \\
\hline$g_{1}$ & 1,0000 & & & & & & \\
\hline$g_{2}$ & $-0,1287$ & 1,0000 & & & & & \\
\hline$g_{3}$ & 0,6178 & $-0,0422$ & 1,0000 & & & & \\
\hline$g_{4}$ & 0,1445 & $-0,1096$ & 0,1725 & 1,0000 & & & \\
\hline$g_{5}$ & 0,1483 & $-0,0674$ & 0,1159 & 0,2332 & 1,0000 & & \\
\hline$g_{6}$ & $-0,2323$ & 0,6572 & $-0,1365$ & $-0,1119$ & $-0,0923$ & 1,0000 & \\
\hline$g_{7}$ & 0,5698 & $-0,2654$ & 0,3527 & 0,1533 & 0,3185 & $-0,3145$ & 1,0000 \\
\hline \multicolumn{8}{|c|}{ DGP IV: distribuição normal com múltiplos outliers (posições sorteadas) } \\
\hline$g_{1}$ & 1,0000 & & & & & & \\
\hline$g_{2}$ & $-0,1136$ & 1,0000 & & & & & \\
\hline$g_{3}$ & 0,6076 & $-0,0291$ & 1,0000 & & & & \\
\hline$g_{4}$ & 0,0127 & $-0,2140$ & 0,0872 & 1,0000 & & & \\
\hline$g_{5}$ & $-0,0389$ & $-0,0080$ & 0,0071 & 0,2143 & 1,0000 & & \\
\hline$g_{6}$ & $-0,2153$ & 0,6551 & $-0,1131$ & $-0,1634$ & $-0,0024$ & 1,0000 & \\
\hline$g_{7}$ & 0,5700 & $-0,2477$ & 0,3365 & 0,0615 & $-0,0562$ & $-0,2866$ & 1,0000 \\
\hline
\end{tabular}

Nota: matriz de correlação gerada a partir das médias das correlações entre condições de momento geradas a partir dos dados de cada DGP em cada replicação, considerando o valor verdadeiro dos parâmetros. 
Tabela B.4 - Testes J, LM e LR de sobreidentificação - Métodos baseados em momentos

\begin{tabular}{cccccc}
\hline & & DGP I & DGP II & DGP III & DGP IV \\
\hline \multirow{2}{*}{ GMM } & Média p-valor teste J & 0,3973 & 0,4355 & 0,3948 & 0,4469 \\
& P-valor teste J < 0,05 & $33,45 \%$ & $26,40 \%$ & $30,55 \%$ & $26,85 \%$ \\
\hline \multirow{3}{*}{ Estimadores } & Média p-valor teste J & 0,0000 & 0,0000 & 0,0000 & 0,0000 \\
GEL/GMC & P-valor teste J < 0,05 & $99,35 \%$ & $99,95 \%$ & $99,55 \%$ & $99,75 \%$ \\
\cline { 2 - 6 } & Média p-valor teste LM & 0,1100 & 0,0905 & 0,1131 & 0,1108 \\
& P-valor teste LM < 0,05 & $64,55 \%$ & $69,80 \%$ & $63,25 \%$ & $66,85 \%$ \\
\cline { 2 - 6 } & Média p-valor teste LR & 0,0603 & 0,0589 & 0,0609 & 0,0718 \\
& P-valor teste LR < 0,05 & $79,80 \%$ & $77,30 \%$ & $78,20 \%$ & $75,25 \%$ \\
\hline
\end{tabular}

Nota: hipótese nula dos testes J, LM e LR = especificação correta (condições de momento são válidas). 
Tabela B.5 - Estatísticas de $\hat{\beta}$

\begin{tabular}{|c|c|c|c|c|c|c|c|c|c|c|c|c|c|c|c|c|}
\hline & \multirow[t]{2}{*}{$\hat{\beta}$} & GMM & EL & ET & CUE & ETEL & $\mathrm{HD}$ & ETHD & SEL & SET & SCUE & SETEL & SHD & SETHD & \multirow{2}{*}{ ML } & \multirow{2}{*}{ BI } \\
\hline \multicolumn{14}{|c|}{ Caso Exatamente Identificado } & & & \\
\hline \multirow{5}{*}{ DGP I } & Média & 0,980202 & 0,980078 & 0,980189 & 0,980193 & 0,948072 & 0,980139 & 0,949710 & 0,980113 & 0,980186 & 0,980201 & 0,947588 & 0,980171 & 0,948761 & 0,969253 & 0,981141 \\
\hline & Mediana & 0,980256 & 0,980000 & 0,980210 & & & & & & & & & & 0,980186 & 0,985471 & 0,981258 \\
\hline & Viés & 0,000202 & 0,000078 & 0,000189 & 0,000193 & $-0,031928$ & 0,000139 & $-0,030290$ & 0,000113 & 0,000186 & 0,000201 & $-0,032412$ & 0,000171 & $-0,031239$ & $-0,010747$ & 0,001141 \\
\hline & EQM & 0,000025 & 0,000032 & 0,000026 & 0,000025 & 0,031716 & 0,000028 & 0,029810 & & 0,000026 & & 0,032200 & 0,000028 & 0,030771 & 0,001354 & 0,000003 \\
\hline & EAM & 0,003931 & 0,003603 & 0,003966 & 0,003971 & 0,036061 & 0,003996 & 0,034450 & 0,003514 & 0,003964 & 0,003967 & 0,036545 & 0,003980 & 0,035406 & 0,025420 & 0,001502 \\
\hline \multirow{5}{*}{ DGP II } & Média & 0,980317 & 0,980663 & 0,980307 & 0,980314 & 0,950247 & 0,980324 & 0,948073 & 0,980701 & 0,980340 & 0,980315 & 0,946758 & 0,980360 & 0,944806 & 0,963870 & 0,981688 \\
\hline & Mediana & 0,980272 & 0,980000 & 0,980229 & 0,980299 & 0,980245 & 0,980228 & 0,980174 & 0,980000 & 0,980210 & 0,980319 & 980164 & 0,980266 & 0,980219 & 979883 & 0,981800 \\
\hline & Viés & 0,000317 & 0,000663 & 0,000307 & 0,000314 & $-0,029753$ & 0,000324 & $-0,031927$ & 0,000701 & 0,000340 & 0,000315 & $-0,033242$ & 0,000360 & $-0,035194$ & $-0,016130$ & 0,001688 \\
\hline & EQM & 0,000051 & 0,000056 & 0,000052 & 0,000051 & 0,02863 & 0,000054 & 0,029954 & 0,000052 & 0,000051 & 0,000052 & 0,032034 & 0,000052 & 0,033277 & 0,001581 & 0,000004 \\
\hline & EAM & 0,005673 & 0,005058 & 0,005693 & 0,005744 & 0,035698 & 0,005714 & 0,037844 & 0,004733 & 0,005644 & 0,005750 & 0,039032 & 0,005661 & 0,041033 & 0,027738 & 0,001845 \\
\hline \multirow{5}{*}{ DGP III } & Média & 0,982165 & 0,981722 & 0,982152 & 0,982186 & 0,951919 & 0,982170 & 0,952232 & 0,981664 & 0,982168 & 0,982187 & 0,951929 & 0,982182 & 0,952254 & 0,970715 & 0,981311 \\
\hline & Mediana & & & & & & & & & & & & & & & \\
\hline & Viés & 0,002165 & 0,001722 & 0,002152 & 0,002186 & $-0,028081$ & 0,002170 & $-0,027768$ & 0,001664 & 168 & 2187 & $-0,028071$ & & $-0,027746$ & $-0,009285$ & 0,001311 \\
\hline & EQM & 0030 & 0,000034 & 0,000030 & 0,0 & 0,029804 & & & & 030 & & & & & 0,001227 & 0,000003 \\
\hline & EAM & 0,004334 & 0,003932 & 0,004349 & 0,004393 & 0,034583 & 0,004391 & 0,034297 & 0,003813 & 0,004346 & 0,004389 & 0,034573 & 0,004392 & 0,03426 & 0,024026 & 0,001565 \\
\hline \multirow{5}{*}{ DGP IV } & Média & 0,979943 & 80186 & 70 & 6 & 9 & 70052 & 6 & 16 & 79970 & 51 & 34493 & 66 & 47 & 964714 & 0,981702 \\
\hline & Mediana & 0,979914 & 0,980000 & 0,979961 & 0 & 00 & 00 & 0,980000 & 000 & 75 & 80 & 000 & 02 & 998 & 980867 & 0,981757 \\
\hline & Viés & $-0,000057$ & & $-0,000080$ & & & & & & & & & & & & \\
\hline & EQM & 0 & 0 , & 64 & 0,0 & 0,0 & 66 & 0,03 & & 62 & 63 & & & & 558 & 004 \\
\hline & EAM & 0,006210 & 0,005552 & 0,006241 & 0,006286 & 0,045813 & 0,006164 & 0,045107 & 0,005208 & 0,006173 & 0,006271 & 0,051552 & 0,006173 & 0,051570 & 0,027472 & 0,001832 \\
\hline \multicolumn{17}{|c|}{ Caso Sobreidentificado } \\
\hline \multirow{5}{*}{ DGP I } & édia & 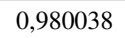 & 0,980161 & & & 0,944520 & 80174 & 0,945539 & 0, & & & & & & - & - \\
\hline & Mediana & 0,979968 & 0,980000 & 80292 & 61 & 219 & 211 & & & & & & & & - & - \\
\hline & Viés & $\mathbf{0 , 0 0 0 0 3 8}$ & 0,000161 & 0,000218 & 97 & & & & & & & & & & - & - \\
\hline & EQM & 0,000029 & 0,000026 & 0,000025 & 0,000025 & 0,035297 & 0,000026 & 0,034340 & 0,00 & 25 & 25 & 0,036730 & 0,000025 & 0,035307 & - & - \\
\hline & EAM & 0,004316 & 0,003291 & 0,003911 & 0,003963 & 0,039577 & 0,003925 & 0,038645 & 0,003274 & 0,003904 & 0,003963 & 0,041014 & 0,003906 & 0,039606 & - & - \\
\hline \multirow{5}{*}{ DGP II } & Média & 0,980187 & 0,980143 & 980303 & 880307 & 0,953273 & 980288 & 0,950850 & 0,980192 & 0,980312 & 0,980276 & 0,946421 & 0,980293 & 0,945478 & - & - \\
\hline & Mediana & 0 , & & 98 & 0,980197 & 0 & & & & & & & & & - & - \\
\hline & Viés & 0,000187 & & & & & & & & & & & & & 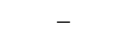 & 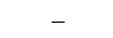 \\
\hline & EQM & 0058 & 0,000048 & 0,000052 & 0,000050 & 0,026950 & 0,000055 & 0,02 & & 052 & & 0,03 & 553 & 0,0 & - & - \\
\hline & EAM & 0,006142 & 0,004083 & 0,005652 & 0,005625 & 0,032777 & 0,005698 & 0,035260 & 0,003846 & 0,005616 & 0,005662 & 0,039508 & 0,005637 & 0,040545 & - & - \\
\hline \multirow{5}{*}{ DGP III } & Média & 0,981652 & 0,981628 & 0,982162 & 0,982186 & 0,960641 & 0,982159 & 0,960445 & 0,981600 & 0,982146 & 0,982192 & 0,958674 & 0,982148 & 0,959024 & - & - \\
\hline & Mediana & 0,981750 & 0,980052 & 8214 & 0,982225 & 0.982045 & & & & & 26 & 0,982023 & 2088 & 0,982086 & - & \\
\hline & Viés & 0,001652 & 0,001628 & 0,002162 & 0,002186 & $-0,019359$ & 0,002159 & $-0,019555$ & 00 & 0,002146 & 0,002192 & $-0,021326$ & 0,002148 & $-0,020976$ & - & - \\
\hline & EQM & & & & & & & & & & & & & & - & \\
\hline & EAM & 0,004499 & 0,003670 & 0,004319 & 0,004357 & 0,025802 & 0,004326 & 0,026085 & 0,003625 & 0,004305 & 0,004364 & 0,027727 & 0,004320 & 0,027511 & - & - \\
\hline \multirow{5}{*}{ DGP IV } & Média & 0,979724 & 980046 & 979963 & 7005 & & 7007 & & & & & & & & - & \\
\hline & Mediana & 0, & & 9920 & & 0 & & & & & & & & 9997 & - & - \\
\hline & Viés & $-0,000276$ & 0,000046 & $-0,000037$ & $-0,000087$ & $-0,039435$ & $-0,000023$ & $-0,038476$ & 0,000121 & $-0,000014$ & $-0,000091$ & $-0,043817$ & 0,000000 & $-0,043760$ & - & - \\
\hline & EQM & & 0 , & & & & & & & & & 0,043397 & 062 & 0,043 & - & - \\
\hline & EAM & 0,006778 & 0,004224 & 0,006206 & 0,006229 & 0,045453 & 0,006120 & 0,044554 & 0,004069 & 0,006133 & 0,006259 & 0,049747 & 0,006091 & 0,049777 & - & - \\
\hline
\end{tabular}

Notas: valor verdadeiro: $\beta=0,98$. EQM: erro quadrático médio. EAM: erro absoluto médio. Melhores desempenhos destacados em negrito. 
Tabela B.6 - Estatísticas de $\hat{\gamma}$

\begin{tabular}{|c|c|c|c|c|c|c|c|c|c|c|c|c|c|c|c|c|}
\hline & \multirow{2}{*}{$\hat{\gamma}$} & GMM & EL & ET & CUE & ETEL & $\mathrm{HD}$ & ETHD & SEL & SET & SCUE & SETEL & SHD & SETHD & \multirow{2}{*}{ ML } & \multirow{2}{*}{ BI } \\
\hline \multicolumn{14}{|c|}{ Caso Exatamente Identificado } & & & \\
\hline \multirow{5}{*}{ DGP I } & Média & 1,799693 & 1,799975 & 1,792883 & 1,801694 & 1,517973 & 1,789484 & 1,520552 & 1,799885 & 1,792690 & 1,801730 & 1,517999 & 1,788053 & 1,521383 & 8,831374 & 1,792836 \\
\hline & Mediana & 1,799847 & 1,800000 & 1,798517 & 1,800003 & 1,797567 & 1,798218 & 1,797667 & 1,800000 & 1,798568 & 1,800000 & 1,797610 & 1,798259 & 1,797722 & 1,800939 & 1,798497 \\
\hline & Viés & $-0,000307$ & $-0,000025$ & $-0,007117$ & 0,001694 & $-0,282027$ & $-0,010516$ & $-0,279448$ & $-0,000115$ & $-0,007310$ & 0,001730 & $-0,282001$ & $-0,011947$ & $-0,278617$ & 7,031374 & $-0,007164$ \\
\hline & EQM & 0,000159 & 0,000457 & 0,005423 & 0,000744 & 0,302007 & 0,005682 & 0,297097 & 0,000390 & 0,005747 & 0,000827 & 0,304036 & 0,005929 & 0,296932 & 201,512589 & 0,008871 \\
\hline & EAM & 0,009969 & 0,008081 & 0,030347 & 0,015673 & 0,296491 & 0,032892 & 0,291800 & $\mathbf{0 , 0 0 7 7 7 3}$ & 0,030736 & 0,015950 & 0,298052 & 0,033481 & 0,291862 & 7,037228 & 0,075397 \\
\hline \multirow{5}{*}{ DGP II } & Média & 1,790962 & 1,802843 & 1,784633 & 1,799995 & 1,562523 & 1,787709 & 1,543238 & 1,802797 & 1,785611 & 1,799233 & 1,557556 & 1,786721 & 1,557903 & 11,134495 & 1,765028 \\
\hline & Mediana & 1,798876 & 1,800000 & 1,796364 & 1,799511 & 1,795352 & 1,796417 & 1,796424 & 1,800000 & 1,796654 & 1,799148 & 1,795845 & 1,796586 & 1,796864 & 1,802347 & 1,771187 \\
\hline & Viés & $-0,009038$ & 0,002843 & $-0,015367$ & $-0,000005$ & $-0,237477$ & $-0,012291$ & $-0,256762$ & 0,002797 & $-0,014389$ & $-0,000767$ & $-0,242444$ & $-0,013279$ & $-0,242097$ & 9,334495 & $-0,034972$ \\
\hline & EQM & 0,009343 & 0,002608 & 0,007473 & 0,001485 & 0,252253 & 0,008455 & 1,003001 & 0,002351 & 0,007396 & 0,002006 & 0,256492 & 0,009235 & 0,256017 & 267,848853 & 0,010563 \\
\hline & EAM & 0,022471 & 0,014061 & 0,040824 & 0,021177 & 0,258409 & 0,041654 & 0,276881 & 0,013076 & 0,042633 & 0,024315 & 0,262812 & 0,046638 & 0,263166 & 9,343180 & 0,080309 \\
\hline \multirow{5}{*}{ DGP III } & Média & 1,804236 & 1,803202 & 1,797763 & 1,805942 & 1,617643 & 1,795489 & 1,615771 & 1,803007 & 1,797153 & 1,805796 & 1,617781 & 1,795471 & 1,616305 & 9,788699 & 1,791399 \\
\hline & Mediana & 1,804486 & 1,800012 & 1,80042 & 1,803724 & 1,799930 & 1,800569 & 1,799717 & 1,800010 & 1,800323 & 1,803240 & 1,799989 & 1,800384 & 1,799834 & 1,801151 & 1,797475 \\
\hline & Viés & 0,004236 & 0,003202 & $-0,002237$ & 0,005942 & $-0,182357$ & $-0,004511$ & $-0,184229$ & 0,003007 & $-0,002847$ & 0,005796 & $-0,182219$ & $-0,004529$ & $-0,183695$ & 7,988699 & $-0,008601$ \\
\hline & EQM & 0,000193 & 0,000811 & 0,005644 & 0,000598 & 0,196766 & 0,006879 & 0,196158 & 0,000833 & 0,005667 & 0,000689 & 0,196022 & 0,007093 & 0,196446 & 228,820304 & 0,008040 \\
\hline & EAM & 0,010722 & 0,009778 & 0,034589 & 0,015518 & 0,203114 & 0,036877 & 0,203922 & 0,009648 & 0,034742 & 0,016012 & 0,202060 & 0,037444 & 0,204179 & 7,991051 & 0,071078 \\
\hline \multirow{5}{*}{ DGP IV } & Média & 1,789161 & 1,800556 & 1,787464 & 1,801799 & 1,51648 & 1,786322 & 1,516122 & 1,800591 & 1,786802 & 1,801877 & 1,519030 & 1,782599 & 119 & 11,041091 & 1,765867 \\
\hline & Mediana & 1,798031 & 1,800 & 1,796905 & 1,799235 & 1,795199 & 1,796815 & 1,79529 & 1,800000 & 1,796737 & 1,799215 & 1,795556 & 1,796533 & 1,795410 & 1,802214 & 1,770485 \\
\hline & Viés & $-0,010839$ & 0,000556 & $-0,012536$ & 0,001799 & $-0,28352$ & $-0,013678$ & $-0,283878$ & 0,000591 & $-0,013198$ & & $-0,280970$ & $-0,0$ & $-0,284581$ & 9,241091 & $-0,034133$ \\
\hline & EQM & 0,012034 & 0,001221 & 0,006067 & 0,001660 & 0,300445 & 0,007903 & 0,300181 & 0,001583 & 0,006921 & 0,002633 & 0,298337 & 0,008742 & 0,299022 & 264,771045 & 0,009900 \\
\hline & EAM & 0,024569 & 0,013409 & 0,040151 & 0,023620 & 0,303472 & 0,042948 & 0,304317 & 0,013033 & 0,042679 & 0,027369 & 0,301683 & 0,046423 & 0,303688 & 9,243935 & 0,078666 \\
\hline \multicolumn{17}{|c|}{ Caso Sobreidentificado } \\
\hline \multirow{5}{*}{ DGP I } & Média & 0,975127 & 9331 & 90890 & 9096 & 45488 & 1,791174 & 1,543650 & 1,799398 & & & 86 & & 40 & - & - \\
\hline & Mediana & 0,802189 & 1,800000 & 1,798327 & 1,799436 & 1,797238 & 1,798465 & 1,797255 & 1,800000 & 1,798364 & 1,799348 & 1,797353 & 1,798663 & 1,797329 & - & - \\
\hline & Viés & $-0,824873$ & $-0,000669$ & $-0,009110$ & $-0,000904$ & $-0,254512$ & $-0,008826$ & $-0,256350$ & $-0,000602$ & $-0,009642$ & $-0,000919$ & $-0,255914$ & $-0,007976$ & $-0,25906$ & - & - \\
\hline & EQM & 0,846990 & 0,000386 & 0,003447 & 0,000529 & 0,268875 & 0,004006 & 0,273178 & 0,000380 & 0,003687 & 0,000545 & 0,270587 & 0,004033 & 0,276147 & - & - \\
\hline & EAM & 0,838655 & 0,007503 & 0,026360 & 0,013817 & 0,264018 & 0,029932 & 0,264879 & $\mathbf{0 , 0 0 7 3 4 8}$ & 0,026980 & 0,014069 & 0,265488 & 0,030121 & 0,267831 & - & - \\
\hline \multirow{5}{*}{ DGP II } & Média & 0,942684 & 1,800607 & 1,785142 & 1,787255 & 1,597989 & 1,785453 & 1,598 & 1,800606 & 1,784 & 1,78 & & 1,78 & 1,58 & - & - \\
\hline & Mediana & 0,760290 & 1,800000 & 1,796400 & 1,797115 & 1,795194 & 1,796195 & & 1,800000 & & 1,796708 & & 1,79 & 1,795643 & - & - \\
\hline & Viés & $-0,857316$ & 0,000607 & $-0,014858$ & $-0,012745$ & $-0,202011$ & $-0,014547$ & $-0,201673$ & 0,000606 & $-0,015985$ & $-0,014930$ & $-0,210846$ & $-0,016016$ & $-0,212231$ & - & - \\
\hline & EQM & 0,862640 & 0,001114 & 0,005384 & 0,003326 & 0,211625 & 0,005592 & 0,208465 & 0,001104 & 0,005685 & 0,003911 & 0,219813 & 0,006165 & 0,219402 & - & - \\
\hline & EAM & 0,860122 & 0,009364 & 0,034491 & 0,027901 & 0,219019 & 0,035744 & 0,215103 & 0,008969 & 0,036143 & 0,030250 & 0,227426 & 0,036803 & 0,226450 & - & - \\
\hline \multirow{5}{*}{ DGP III } & Média & 1025254 & 1,803290 & 1,794459 & 1,803422 & 1614435 & 1,794884 & 1,614503 & 1,803445 & 1,794349 & 1,803941 & 1,609770 & 1,794074 & 1,609564 & - & - \\
\hline & Mediana & 0,901899 & 1,800022 & 1,800329 & 1,80242 & 1,799357 & 1,800497 & 1,799078 & 1,800019 & 1,800276 & 1,802420 & 1,799118 & 1,800410 & 1,799221 & - & - \\
\hline & Viés & $-0,774746$ & 0,003290 & $-0,005541$ & 0,003422 & $-0,185565$ & $-0,005116$ & $-0,185497$ & & $-0,005651$ & 0,003941 & $-0,190230$ & $-0,005926$ & $-0,190436$ & - & - \\
\hline & EQM & 0,760407 & 0,000518 & 0,003611 & 0,000688 & 0,194829 & 0,003873 & 0,194965 & 0,000500 & 0,003689 & 0,000718 & 0,199175 & 0,003993 & 0,200495 & - & - \\
\hline & EAM & 0,782170 & 0,008422 & 0,028404 & 0,014609 & 0,199120 & 0,029348 & 0,199320 & 0,008289 & 0,028818 & 0,014991 & 0,202940 & 0,029664 & 0,204362 & - & - \\
\hline \multirow{5}{*}{ DGP IV } & Média & 0,898878 & 1,799869 & 1,781688 & 1,788705 & 1,546246 & 1,785396 & 1,551558 & 1,800094 & 1,781010 & 1,785889 & 1,538394 & 1,782554 & 1,54225 & - & - \\
\hline & Mediana & 15955 & 1,800000 & 1,796789 & 1,797067 & 1,793437 & 1,796818 & 1,794452 & 1,800000 & 1,796731 & 1,797058 & 1,794026 & 1,796687 & 1,794737 & - & - \\
\hline & Viés & $-0,901122$ & $-0,000131$ & $-0,018312$ & $-0,011295$ & $-0,253754$ & $-0,014604$ & $-0,248442$ & 0,000094 & $-0,018990$ & $-0,014111$ & $-0,261606$ & $-0,017446$ & $-0,257750$ & - & - \\
\hline & EQM & 0,929671 & & 0,009571 & & 0,260248 & 0,007289 & 0,258372 & 0,000634 & 0,009999 & 0,003348 & 0,269271 & 0,008165 & 0,269135 & - & - \\
\hline & EAM & 0,902122 & 0,009113 & 0,039962 & 0,026311 & 0,264210 & 0,037998 & 0,260744 & 0,008555 & 0,041524 & 0,029143 & 0,272321 & 0,041261 & 0,270135 & - & - \\
\hline
\end{tabular}

Notas: valor verdadeiro: $\gamma=1,8$. EQM: erro quadrático médio. EAM: erro absoluto médio. Melhores desempenhos destacados em negrito. 
Tabela B.7 - Estatísticas de $\hat{b}$

\begin{tabular}{|c|c|c|c|c|c|c|c|c|c|c|c|c|c|c|c|c|}
\hline & $\hat{b}$ & GMM & EL & ET & CUE & ETEL & $\mathrm{HD}$ & ETHD & SEL & SET & SCUE & SETEL & SHD & SETHD & \multirow{2}{*}{ ML } & \multirow{2}{*}{ BI } \\
\hline \multicolumn{15}{|c|}{ Caso Exatamente Identificado } & & \\
\hline \multirow{5}{*}{ DGP I } & Média & 3.199884 & 3.199865 & 3.193806 & 3.202063 & 3.413509 & 3.190354 & 3.462055 & 3.199669 & 3.193654 & 3.202062 & 3.414318 & 3.188867 & 3.461894 & 3.200015 & 3.202415 \\
\hline & Mediana $b$ & 3.200125 & 3.200000 & 3.199589 & 3.200475 & 3.200059 & 3.199401 & 3.200000 & 3.200000 & 3.199560 & 3.200475 & 3.200100 & 3.199290 & 3.199999 & 3.200000 & 3.201663 \\
\hline & Viés b & -0.000116 & -0.000135 & -0.006194 & 0.002063 & 0.213509 & -0.009646 & 0.262055 & -0.000331 & -0.006346 & 0.002062 & 0.214318 & -0.011133 & 0.261894 & 0.000015 & 0.002415 \\
\hline & EQM b & 0.000146 & 0.000506 & 0.006782 & 0.000740 & 0.828345 & 0.006190 & 1.072016 & 0.000450 & 0.007245 & 0.000795 & 0.833280 & 0.006363 & 1.072546 & 0.000077 & 0.004821 \\
\hline & EAM b & 0.009543 & 0.007671 & 0.031598 & 0.015050 & 0.419455 & 0.033241 & 0.493976 & 0.007374 & 0.032265 & 0.015234 & 0.421944 & 0.033766 & 0.493878 & 0.000675 & 0.054850 \\
\hline \multirow{5}{*}{ DGP II } & Média & 3.193172 & 3.202944 & 3.186207 & 3.201210 & 3.465549 & 3.189102 & 3.462018 & 3.202640 & 3.187141 & 3.200331 & 3.464307 & 3.188125 & 3.463299 & 3.199069 & 3.202298 \\
\hline & Mediana & 3.199940 & 3.200000 & 3.199230 & 3.200403 & 3.200053 & 3.199283 & 3.200083 & 3.200000 & 3.199033 & 3.200015 & 3.200027 & 3.199096 & 3.200060 & 3.200001 & 3.202706 \\
\hline & Viés & -0.006828 & 0.002944 & -0.013793 & 0.001210 & 0.265549 & -0.010898 & 0.262018 & 0.002640 & -0.012859 & 0.000331 & .264307 & -0.011875 & .263299 & -0.000931 & .002298 \\
\hline & EQM & 0.005595 & 0.002546 & 0.007847 & 0.001503 & 0.697829 & 0.008611 & 0.681449 & 0.002331 & 0.008440 & 0.001915 & 0.730616 & 0.009693 & 0.708161 & 0.001380 & 0.004512 \\
\hline & EAM & 0.020851 & 0.013128 & 0.041392 & 0.020983 & 0.389054 & 0.041827 & 0.385872 & 0.012139 & 0.043785 & 0.023493 & 0.399738 & 0.047224 & 0.396107 & 0.001667 & 0.053449 \\
\hline \multirow{5}{*}{ DGP III } & Médi & 195213 & 07150 & 3,18985 & 32 & 276241 & 3,187668 & 22 & 0 & 51 & 83 & 58 & 318 & 54 & 11 & 73 \\
\hline & Mediana & 3,195590 & 3,199981 & 3,197738 & 3,197364 & 3,197940 & 3,197496 & 3,197652 & 3,199990 & 3,197682 & 3,197467 & 3,197975 & 3,197585 & 197748 & 3,200000 & ,204919 \\
\hline & Viés & $-0,004787$ & $-0,002841$ & $-0,010150$ & $-0,002868$ & 0,076241 & & 0,080302 & & $-0,010849$ & & & & & & 0,005173 \\
\hline & EQM & $\mathbf{0 , 0 0 0 1 8 9}$ & 0,000788 & 0,006016 & 0,000523 & 0,650395 & 0,007434 & 0,765980 & 0,000820 & 0,006031 & 0,000605 & 0,659612 & 0,007678 & 0,775130 & 0,002022 & 004634 \\
\hline & EAM & 0,010496 & 0,008899 & 0,035644 & 0,014690 & 0,319243 & 0,038253 & 0,351515 & 0,008853 & 0,035874 & 0,015123 & 0,321441 & 0,039104 & 0,353929 & 0,002041 & 0,053944 \\
\hline \multirow{5}{*}{ DGP IV } & Média & 4011 & 26 & 3190618 & 3.204899 & 3.463513 & 162 & 84 & 103 & 189636 & 205004 & .461549 & 3.185192 & 466104 & 3.200931 & 3.204142 \\
\hline & Mediana & & & & & & & & & & & & & & & 4788 \\
\hline & Viés & -0.005989 & 0.001326 & -0.009382 & 0.004899 & 0.263513 & -0.010838 & 0.269584 & 103 & -0.010364 & 0.005004 & 0.261549 & -0.014808 & 104 & 0.000931 & .004142 \\
\hline & EQM & 0.007760 & & & & 0.813066 & & & & & & & & & 0950 & .004668 \\
\hline & EAM & 0.022339 & 0.012600 & 0.038946 & 0.022482 & 0.452491 & 0.041931 & 0.463055 & 0.012175 & 0.041362 & 0.026344 & .454318 & 0.045508 & 466301 & 0.001952 & 0.054291 \\
\hline \multicolumn{17}{|c|}{ Caso Sobreidentificado } \\
\hline \multirow{5}{*}{ DGP I } & Média & 2 & $J$ & 3.191114 & 3.199251 & 3 & 1413 & 3.272090 & 210 & 3.190531 & 1 & 43 & & 7 & - & \\
\hline & Mediana & 2.311940 & 3.200000 & 166 & & & & & & & & & & & - & \\
\hline & Viés & -0.735526 & -0.000732 & -0.008886 & -0.000749 & 0.114573 & -0.008587 & 0.072090 & -0.000746 & -0.009469 & -0.000739 & 0.114343 & -0.007720 & 0.071027 & - & - \\
\hline & EQM & 0.656621 & 0.000392 & 0.003665 & 0.000532 & 0.65917 & & & & & & 0.667537 & & & - & - \\
\hline & EAM & 0.749113 & 0.007005 & 0.026886 & 0.013665 & 0.350254 & 0.029572 & 0.327359 & 0.006917 & 0.027364 & 0.013814 & 0.353666 & 0.029908 & 0.330982 & - & - \\
\hline \multirow{5}{*}{ DGP II } & Mádi. & 2422100 & 200452 & 186176 & 10817 & 20201 & 186660 & $217+4$ & 200026 & 10500 & 21050 & 2005 & 3.185294 & 347084 & 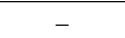 & - \\
\hline & Mediana & 2.279735 & 3.200000 & 98486 & 88995 & 3.199612 & 3.198932 & 654 & 000 & & & 465 & 3.1 & 654 & - & - \\
\hline & Viés & -0.766900 & 0.000452 & -0.013824 & -0.011826 & 0.193048 & -0.013340 & 449 & & & 059 & 0.198548 & -0.0 & 0.1 & - & - \\
\hline & EQM & 0.673377 & 0.001020 & 0.004908 & 0.003183 & 0.654895 & 0.005498 & 0.555907 & 005 & 0.005434 & 0.003705 & 0.681973 & 0.006158 & 0.583170 & - & - \\
\hline & EAM & 0.769747 & 0.008557 & 0.033594 & 0.027396 & 0.346905 & 0.034744 & 0.304845 & 0.008126 & 0.035366 & 0.029322 & 0.359956 & 0.035966 & 0.318940 & - & - \\
\hline \multirow{5}{*}{ DGP III } & Médic & 2,502882 & 3,197154 & 318606 & 3,194563 & 3,215490 & 3,186630 & 183700 & 197525 & 3,186041 & 3,195114 & 3,219098 & 3,185896 & 3,191682 & - & - \\
\hline & Mediana & 2,387652 & 3,199984 & 3,197326 & 3,196381 & 3,197470 & 3,197393 & 3,197174 & 3,199985 & 3,197486 & 3,196587 & 3,197487 & 3,197393 & 3,197343 & - & - \\
\hline & Viés & $-0,697118$ & $-0,002846$ & $-0,013940$ & $-0,005437$ & 0,015490 & $-0,013370$ & $-0,016300$ & $-0,002475$ & $-0,013959$ & $-0,004886$ & 0,019098 & $-0,014104$ & $-0,008318$ & - & 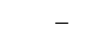 \\
\hline & EQM & 0,594862 & 0,000472 & 0,003889 & 0,000701 & 0,611752 & 0,004217 & 0,595892 & 0,000429 & 0,003979 & 0,000756 & 0,614552 & 0,004335 & 0,602757 & - & - \\
\hline & EAM & 0,703704 & 0,007846 & 0,029354 & 0,014481 & 0,304345 & 0,030416 & 0,287495 & 0,007619 & 0,029846 & 0,014909 & 0,307208 & 0,030780 & 0,291867 & - & - \\
\hline \multirow{5}{*}{$b$} & Média & 2.397272 & 3.200627 & 3.184836 & 3.19154 & 3.395873 & 3.188472 & 3.369161 & 3.200856 & 3.184097 & 3.188642 & 3.40247 & 3.185503 & 3.365204 & - & - \\
\hline & Mediana & 2.269591 & 0000 & 8878 & 785 & & 3. & & 000 & & 663 & 3.199588 & & 3.199674 & - & - \\
\hline & Viés & -0.802728 & 0.000627 & -0.015164 & -0.00846 & 0.195873 & -0.011528 & 0.169161 & 0.000856 & -0.015903 & -0.011358 & 0.202470 & -0.014497 & 0.165204 & - & - \\
\hline & EQM & & & & & & & & 655 & & & 0.8 & & 4879 & - & - \\
\hline & EAM & 0.803583 & 0.008563 & 0.038011 & 0.025349 & 0.440137 & 0.036970 & 0.408439 & 0.008090 & 0.039594 & 0.028180 & 0.444492 & 0.040060 & 0.413237 & - & - \\
\hline
\end{tabular}

Notas: valor verdadeiro: $b=3,2$. EQM: erro quadrático médio. EAM: erro absoluto médio. Melhores desempenhos destacados em negrito. 
Tabela B.8 - Estatísticas de $\hat{\rho}$

\begin{tabular}{|c|c|c|c|c|c|c|c|c|c|c|c|c|c|c|c|c|}
\hline & \multirow{2}{*}{$\hat{\rho}$} & GMM & EL & ET & CUE & ETEL & HD & ETHD & SEL & SET & SCUE & SETEL & SHD & SETHD & \multirow{2}{*}{ ML } & \multirow{2}{*}{ BI } \\
\hline & & \multicolumn{13}{|c|}{ Caso Exatamente Identificado } & & \\
\hline \multirow{5}{*}{ DGP I } & Media & 0.977691 & 0.905463 & 0.962346 & 0.970118 & 0.930628 & 0.955653 & 0.911981 & 0.905313 & 0.962104 & 0.970083 & 0.929392 & 0.954724 & 0.909244 & 0.885215 & 0.882414 \\
\hline & Mediana & 1.000000 & 0.900010 & 0.994497 & 0.999792 & 0.903631 & 0.984479 & 0.932966 & 0.900008 & 0.994402 & 0.999711 & 0.904164 & 0.983456 & 0.931873 & 0.890047 & 0.883143 \\
\hline & Vies & 0.077691 & 0.005463 & 0.062346 & 0.070118 & 0.030628 & 0.055653 & 0.011981 & 0.005313 & 0.062104 & 0.070083 & 0.029392 & 0.054724 & 0.009244 & -0.014785 & -0.017586 \\
\hline & EQM & 0.022264 & 0.000752 & 0.008883 & 0.016600 & 0.010309 & 0.005672 & 0.044984 & 0.000732 & 0.008707 & 0.016132 & 0.012004 & 0.005912 & 0.049510 & 0.001486 & 0.000795 \\
\hline & EAM & 0.100184 & 0.008380 & 0.068069 & 0.090834 & 0.049667 & 0.057399 & 0.078945 & $\mathbf{0 . 0 0 8 1 3 8}$ & 0.067771 & 0.089397 & 0.050531 & 0.057942 & 0.080793 & 0.027179 & 0.022399 \\
\hline \multirow{5}{*}{ DGP II } & Media & 0.983091 & 0.907387 & 0.967626 & 979253 & 0.891216 & 0.964043 & 0.842339 & 0.906715 & 0.967469 & 0.979118 & 0.895209 & 0.964862 & 0.846937 & 0.889877 & 0.880486 \\
\hline & Mediana & 1.000000 & 0.900043 & 0.996573 & 1.000000 & 0.957732 & 0.993501 & 0.969795 & 0.900025 & 0.996124 & 1.000000 & 0.955016 & 0.994403 & 0.961090 & 0.894430 & 0.881699 \\
\hline & Vies & 0.083091 & 0.007387 & 0.067626 & 0.079253 & -0.008784 & 0.064043 & -0.057661 & 0.006715 & 0.067469 & 0.079118 & -0.004791 & 0.064862 & -0.053063 & -0.010123 & -0.019514 \\
\hline & EQM & 0.014973 & 0.000569 & 0.008469 & 0.013388 & 0.085466 & 0.006586 & 0.167418 & 0.000547 & 0.008481 & 0.012713 & 0.081810 & 0.006852 & 0.162462 & 0.001148 & 0.000867 \\
\hline & EAM & 0.096762 & 0.009289 & 0.072392 & 0.094864 & 0.109091 & 0.066234 & 0.161276 & 0.008889 & 0.072837 & 0.094106 & 0.103914 & 0.068112 & 0.154297 & 0.025078 & 0.023813 \\
\hline \multirow{5}{*}{ DGP III } & Média & 64 & 79 & 91 & 0,973547 & 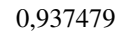 & 3 & 0,928809 & 6 & 1 & 3 & 5 & 8 & 9 & 16 & 34 \\
\hline & Mediana & 1,000000 & 0,900023 & 0,995427 & 0,999768 & 0,941139 & 34 & 0,967216 & 0,900018 & 0,995646 & 0,99973 & 0,936131 & 0,990763 & 963602 & 889886 & 882761 \\
\hline & Viés & 0,083464 & 0,008279 & 0,066591 & 0,073547 & 0,037479 & 0,061133 & 0,028809 & 0,007856 & 0,066431 & 0,073083 & 0,035635 & 0,061078 & & $-0,013954$ & $-0,018466$ \\
\hline & EQM & 0,013369 & 0,000791 & 0,009222 & 0,014312 & 0,011114 & 0,005897 & 0,037216 & 0,000762 & 0,009285 & 0,014579 & 0,011180 & 0,005861 & 0,033622 & 0,001299 & 0,000786 \\
\hline & EAM & 0,095871 & 0,010349 & 0,071642 & 0,091117 & 0,056678 & 0,062294 & 0,075437 & 0,009907 & 0,072016 & 0,090623 & 0,056398 & 0,062083 & 0,073001 & 0,026841 & 0,022367 \\
\hline \multirow{5}{*}{ DGP IV } & Media & 79796 & 09221 & 68372 & 74015 & 99 & 0 & & 104 & 34 & 44 & & & & 80 & 70 \\
\hline & Mediana & 1.000000 & 0.900084 & 0.996954 & 1.000000 & 0.943716 & 0.993773 & 0.954769 & 0.900052 & 0.996397 & 1.000000 & 0.938282 & 0.993448 & 269 & 0.893572 & 0.881925 \\
\hline & Vies & 0.079796 & 0.009221 & 0.068372 & 0.074015 & -0.045001 & 0.063270 & -0.086218 & 0.008104 & 0.068334 & 0.075644 & 236 & 662 & -0.0 & -0.011120 & -0.019930 \\
\hline & EQM & 0.020388 & 0.000718 & 0.009075 & 0.020190 & 0.140881 & 0.008171 & 0.208962 & 0.000642 & 0.007490 & 0.017339 & 0.117756 & 0.008243 & 0.19 & 0.001177 & 0.000858 \\
\hline & EAM & 0.099718 & 0.011255 & 0.073655 & 0.099071 & 0.138513 & 0.067489 & 0.184734 & 0.010266 & 0.072735 & 0.097025 & 0.124287 & 0.067656 & 0.170615 & 0.024973 & 0.023359 \\
\hline \multicolumn{17}{|c|}{ Caso Sobreidentificado } \\
\hline \multirow{5}{*}{ DGP I } & Media & 71423 & 34 & 25 & 71 & 9 & 3181 & & 392 & 8 & & 1 & 52 & 9 & - & 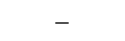 \\
\hline & Mediana & 1.000000 & 0.900018 & 88313 & 078 & & 957 & & & & & & & & - & - \\
\hline & Vies & 0.071423 & 0.007334 & 0.055125 & 0.066771 & 0.023309 & 0.053181 & 0.027752 & 0.007392 & 0.055498 & 0.069082 & 0.021761 & 0.053352 & 0.026929 & - & - \\
\hline & EQM & 0.032857 & 0.000579 & 0.005692 & 0.021110 & 0.016934 & 0.005429 & 0.017052 & 0.000582 & 0.005694 & 0.017261 & 0.017468 & 0.005416 & 0.018445 & - & - \\
\hline & EAM & 0.110686 & 0.008741 & 0.057917 & 0.091781 & 0.049096 & 0.055535 & 0.050273 & 0.008743 & 0.058081 & 0.089548 & 0.049865 & 0.055515 & 0.051434 & - & - \\
\hline \multirow{5}{*}{ DGP II } & Media & 0.984962 & 0.905206 & 0.961616 & 74132 & 8238 & 57846 & & 05271 & 61614 & 46 & 91 & 39 & & - & - \\
\hline & Mediana & 1.000000 & 0.900014 & 0.992815 & 0.998447 & 0.930982 & 510 & 5006 & 012 & 0.993100 & 0.998875 & 941 & & & - & - \\
\hline & Vies & 0.084962 & 0.005206 & 0.061616 & 0.074132 & -0.001762 & 0.057846 & 0.010704 & 0.005271 & 0.061614 & 0.070946 & -0.008709 & 0.057539 & 0.006623 & - & _ \\
\hline & EQM & 0.015531 & 0.000503 & 0.006219 & 0.011436 & 0.064198 & 0.005920 & 0.050394 & 0.000495 & 0.006357 & 0.015586 & 0.072985 & 0.005999 & 0.055186 & - & - \\
\hline & EAM & 0.099427 & 0.007250 & 0.064257 & 0.085275 & 0.090168 & 0.060907 & 0.079972 & 0.007173 & 0.064724 & 0.089913 & 0.095598 & 0.061396 & 0.083465 & - & - \\
\hline \multirow{5}{*}{ DGP III } & Média & 0,979996 & 0,908979 & 0,960402 & 0,975061 & 8549 & 56217 & 0,938197 & 0,908497 & 0,960488 & 975037 & 77 & 24 & 1 & - & - \\
\hline & Mediana & 1,000000 & 0,900032 & 0,992275 & 0,999567 & 0,913514 & 0,988456 & 0,928359 & 0,900028 & 0,992414 & 0,999541 & 103 & 0,986951 & 0,928539 & - & - \\
\hline & Viés & 0,079996 & 0,008979 & 0,060402 & 0,075061 & 0,028549 & 0,056217 & 0,038197 & 0,008497 & 0,060488 & 0,075037 & 0,027877 & 0,055824 & 0,037631 & - & - \\
\hline & EQM & 0,019546 & 0,000743 & 0,005994 & 0,012375 & 0,014513 & 0,005457 & 0,009831 & 0,000704 & 0,006001 & 0,011825 & 0,013927 & 0,005418 & 0,010165 & - & - \\
\hline & EAM & 0,102501 & 0,010903 & 0,062288 & 0,087863 & 0,054327 & 0,057096 & 0,051131 & $\mathbf{0 , 0 1 0 4 2 3}$ & 0,062382 & 0,087803 & 0,054147 & 0,056790 & 0,051730 & - & - \\
\hline \multirow{5}{*}{ DGP IV } & Medi & 0.981881 & 0.906336 & 0.963176 & 0.972500 & 0.886856 & 0.957106 & 0.895314 & 0.906244 & 0.961497 & 0.970139 & 87712 & 0.956900 & 896953 & - & - \\
\hline & Mediana & 1.000000 & 0.900020 & 0.994575 & 0.999072 & 0.940234 & 0.991419 & 0.939497 & 0.900022 & 0.993835 & 0.999204 & 0.932461 & 0.990061 & 0.935243 & - & - \\
\hline & Vies & 0.081881 & 0.00633 & 0.063176 & 0.072500 & -0.013144 & 0.057106 & -0.004686 & 0.006244 & 0.061497 & 0.070139 & -0.012288 & 0.056900 & -0.003047 & - & - \\
\hline & EQM & 0.019329 & 0.000571 & 0.007360 & 0.014045 & 0.084768 & 0.007660 & 0.069426 & 0.000520 & 0.008019 & 0.018071 & 0.078494 & 0.006440 & 0.066003 & - & - \\
\hline & EAM & 0.102318 & 0.008507 & 0.067331 & 0.087282 & 0.105202 & 0.063787 & 0.097084 & 0.008102 & 0.068038 & 0.090569 & 0.101745 & 0.062860 & 0.094515 & - & - \\
\hline
\end{tabular}


Tabela B.9 - Estatísticas de $\hat{\sigma}$

\begin{tabular}{|c|c|c|c|c|c|c|c|c|c|c|c|c|c|c|c|c|}
\hline & $\hat{\sigma}$ & GMM & EL & ET & CUE & ETEL & HD & ETHD & SEL & SET & SCUE & SETEL & SHD & SETHD & \multirow{2}{*}{ ML } & \multirow{2}{*}{ BI } \\
\hline \multicolumn{15}{|c|}{ Caso Exatamente Identificado } & & \\
\hline \multirow{5}{*}{ DGP I } & Média & 0,003810 & 0,006412 & 0,004104 & 0,004245 & 0,018494 & 0,004453 & 0,017820 & 0,006408 & 0,004076 & 0,004246 & 0,018021 & 0,004495 & 0,017997 & 0,008057 & 0,006648 \\
\hline & Mediana & 0,004663 & 0,006949 & 0,004769 & 0,004748 & 0,006991 & & 0,006979 & 0,006949 & & & 0,006992 & 0,005130 & 0,006982 & 0,006863 & 0,006621 \\
\hline & Viés & $-0,003190$ & $-0,000588$ & $-0,002896$ & $-0,002755$ & 0,011494 & $-0,002547$ & 0,010820 & $-0,000592$ & $-0,002924$ & $-0,002754$ & 0,011021 & $-0,002505$ & 0,010997 & 0,001057 & $-0,000352$ \\
\hline & EQM & 0,000026 & 0,000004 & 0,000020 & 0,000020 & 0,017209 & 0,000020 & 0,016273 & 0,000005 & 0,000020 & 0,000020 & 0,015871 & 0,000020 & 0,016284 & 0,000013 & 0,000000 \\
\hline & EAM & 0,003670 & 0,000904 & 0,003283 & 0,003270 & 0,014925 & 0,003024 & 0,014594 & 0,000910 & 0,003291 & 0,003246 & 0,014387 & 0,003016 & 0,014745 & 0,002164 & 0,000451 \\
\hline \multirow{5}{*}{ DGP II } & Média & 0.007011 & 0.007122 & 0.005744 & 0.006869 & 0.027836 & 0.005742 & 0.020027 & 0.007111 & 0.005821 & 0.006797 & 0.035098 & 0.005889 & 0.021075 & 0.012112 & 0.009219 \\
\hline & Mediana & 0.006827 & 0.007000 & 0.006928 & 0.006832 & 0.007000 & 0.006970 & 0.006997 & 0.007000 & 0.006942 & 0.006837 & 0.007000 & 0.006971 & 0.006998 & 0.012059 & 0.009062 \\
\hline & Vies & 0.000011 & 0.000122 & -0.001256 & -0.000131 & 0.020836 & -0.001258 & 0.013027 & 0.000111 & -0.001179 & -0.000203 & 0.028098 & -0.001111 & 0.014075 & 0.005112 & 0.002219 \\
\hline & EQM & 0.000010 & 0.000002 & 0.000016 & 0.000019 & 0.027185 & 0.000016 & 0.020234 & 0.000002 & 0.000017 & 0.000014 & 0.040630 & 0.000019 & 0.020671 & 0.000048 & .000006 \\
\hline & EAM & 0.001267 & 0.000638 & 0.002563 & 0.001665 & 0.024443 & 0.002591 & 0.016931 & 0.000656 & 0.002621 & 0.001658 & 0.031609 & 0.002709 & 0.017945 & 0.005135 & 0.002219 \\
\hline \multirow{5}{*}{ DGP III } & Média & 0,004237 & 0,006413 & 0,004107 & 0,004577 & 0,020065 & 0,004313 & 0,01824 & 0,006436 & 0,004104 & 0,004609 & 0,017441 & 0,004335 & 0,019308 & 0,008654 & 0,007018 \\
\hline & Mediana & 0,00 & & & & & & & & & & & & & 545 & 007024 \\
\hline & Viés & $-0,002763$ & $-0,000587$ & $-0,002893$ & $-0,002423$ & 0,013065 & $-0,00$ & 0,011240 & $-0,000564$ & 896 & 391 & & 2665 & & 0,001654 & 000018 \\
\hline & EQM & 0,000017 & 0,000003 & 0,000021 & 0,000017 & 0,019542 & 0,000019 & 0,017779 & 0,000003 & 0,000021 & 0,00 & & 0,000019 & 0,019712 & 0,000019 & 0,000000 \\
\hline & EAM & 0,002999 & 0,000802 & 0,003292 & 0,002905 & 0,016525 & 0,003060 & 0,015196 & 0,000789 & 0,003308 & 0,002886 & 0,013876 & 0,003053 & 0,016259 & 0,002397 & 0,000358 \\
\hline \multirow{5}{*}{ DGP IV } & Média & 0,006987 & 0,007145 & 0,005701 & 0,006995 & 0,021887 & 5697 & 0,017672 & 007121 & 0,005708 & 0,006927 & 0,025074 & 0,005787 & 0,017221 & 0,012070 & 0,009144 \\
\hline & Mediana & 0,006846 & & & & & & & & & & & & & & \\
\hline & Viés & $-0,000013$ & 0,000145 & $-0,001299$ & $-0,000005$ & 0,014887 & $-0,001303$ & 0,010672 & 0,000121 & $-0,001292$ & $-0,000073$ & 074 & $-0,001213$ & 0,010221 & 0,005070 &, 002144 \\
\hline & EQM & & & & & & 0,000018 & & & & & & & & 055 & 0,000005 \\
\hline & EAM & 0,001266 & 0,000671 & 0,002529 & 0,001641 & 5523 & 0,002535 & 0,014474 & 0,000692 & 0,002412 & 0,001604 & 0,021612 & 0,002600 & 0,013984 & 0,005082 & 0,002144 \\
\hline \multicolumn{17}{|c|}{ Caso Sobreidentificado } \\
\hline \multirow{5}{*}{ DGP I } & (a) & & & & & & 34451 & 1170 & 0,006 & & & & & & - & \\
\hline & Mediana & 0 & 32 & 16 & 05 & 81 & & & & & & & 0,0 & & 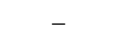 & - \\
\hline & Viés & $-0,001894$ & $-0,000725$ & $-0,002447$ & $-0,002335$ & 0,013639 & $-0,002$ & & $-0,000721$ & & 407 & & $-0,002541$ & 0,0 & - & 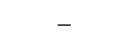 \\
\hline & EQM & 0,000018 & 0,000003 & 15 & 0,000024 & 06 & 16 & & & 15 & 0,00 & 00 & 0,0 & 0,01 & - & - \\
\hline & EAM & 0,002544 & 0,000844 & 0,002719 & 0,003029 & 0,016779 & 0,002834 & 0,013127 & 0,000837 & 0,002758 & 0,002966 & 0,016854 & 0,002841 & 0,012563 & - & - \\
\hline \multirow{5}{*}{ DGP II } & Média & 0.006964 & 07104 & 06187 & 0.006851 & 28620 & T $>$ & 0.021861 & 2 & & 27 & 94 & 30 & 82 & - & - \\
\hline & Mediana & 0. & & & & & & & & & & & & & - & - \\
\hline & Vies & -0.000036 & 00104 & -0.000813 & -0.000149 & & -0.000900 & & 102 & -0.0 & & & 870 & 1782 & - & - \\
\hline & EQM & 0.000008 & 0.000002 & 0.000012 & 0.000011 & 0.031451 & 0.000014 & 0.021 & 002 & 0.000 & 0.000 & & 0.000014 & 0.02 & - & - \\
\hline & EAM & 0.001091 & 0.000562 & 0.002035 & 0.001488 & 0.024862 & 0.002199 & 0.018187 & 0.000557 & 0.002138 & 0.001644 & 0.028764 & 0.002284 & 0.021316 & - & - \\
\hline \multirow{5}{*}{ DGP III } & Média & 0,005304 & 06376 & 0,004549 & 0,004785 & 20496 & 29 & 0 , & 0,006389 & 882 & 0,0 & 792 & 0,004743 & 35 & - & - \\
\hline & Mediana & & & & & & & & & & & & 598 & & - & - \\
\hline & Viés & $-0,001696$ & $-0,000624$ & $-0,002451$ & $-0,002215$ & 0,013496 & $-0,002271$ & 0,008126 & $-0,000611$ & $-0,002418$ & $-0,002218$ & 0,011792 & $-0,002257$ & 0,006350 & - & - \\
\hline & EQM & & 0,000002 & & & & & & 0,000002 & & & & & & - & - \\
\hline & EAM & 0,002098 & 0,000740 & 0,002732 & 0,002550 & 0,016568 & 0,002594 & 0,011308 & 0,000736 & 0,002726 & 0,002538 & 0,014832 & 0,002570 & 0,009542 & - & - \\
\hline \multirow{5}{*}{ DGP IV } & Média & 0,007122 & 007073 & 0,006165 & 0,006803 & 0,035439 & 0,006127 & 0,015 & 093 & 84 & 0,006956 & 0,038059 & 052 & 01 & - & - \\
\hline & Mediana & 817 & 000 & & 6869 & 000 & & & 000 & & & 000 & 99 & 1000 & - & - \\
\hline & Viés & 0,000122 & 0,000073 & $-0,000835$ & $-0,000197$ & 0,028439 & $-0,000873$ & 0,008132 & 0,000093 & $-0,000816$ & $-0,000044$ & 0,031059 & $-0,000948$ & 0,016901 & - & - \\
\hline & EQM & 0,000012 & 0,000002 & 0,000012 & 0,000014 & 050 & 0,000014 & 0,009311 & 002 & 014 & 0,0 & 360 & 0,000013 & 4994 & - & - \\
\hline & EAM & 0,001075 & 0,000548 & 0,001931 & 0,001405 & 0,031775 & 0,002118 & 0,011626 & 0,000561 & 0,002087 & 0,001464 & 0,034464 & 0,002218 & 0,020501 & - & - \\
\hline
\end{tabular}

Notas: valor verdadeiro: $\sigma=0,007$. EQM: erro quadrático médio. EAM: erro absoluto médio. Melhores desempenhos destacados em negrito. 


\section{Figura B.1 - Distribuicão de $\hat{\beta}$}
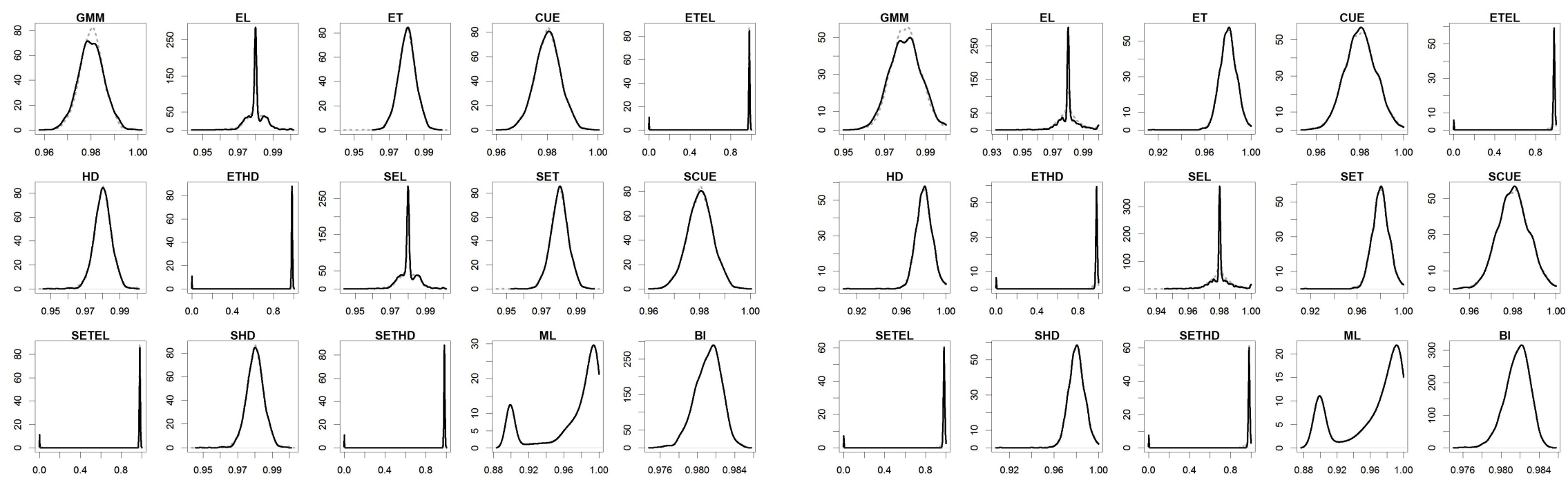

(a) DGP I: distribuição normal
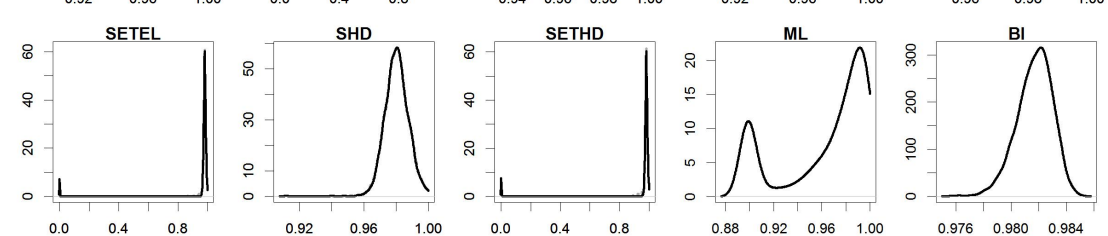

(b) DGP II: distribuição t
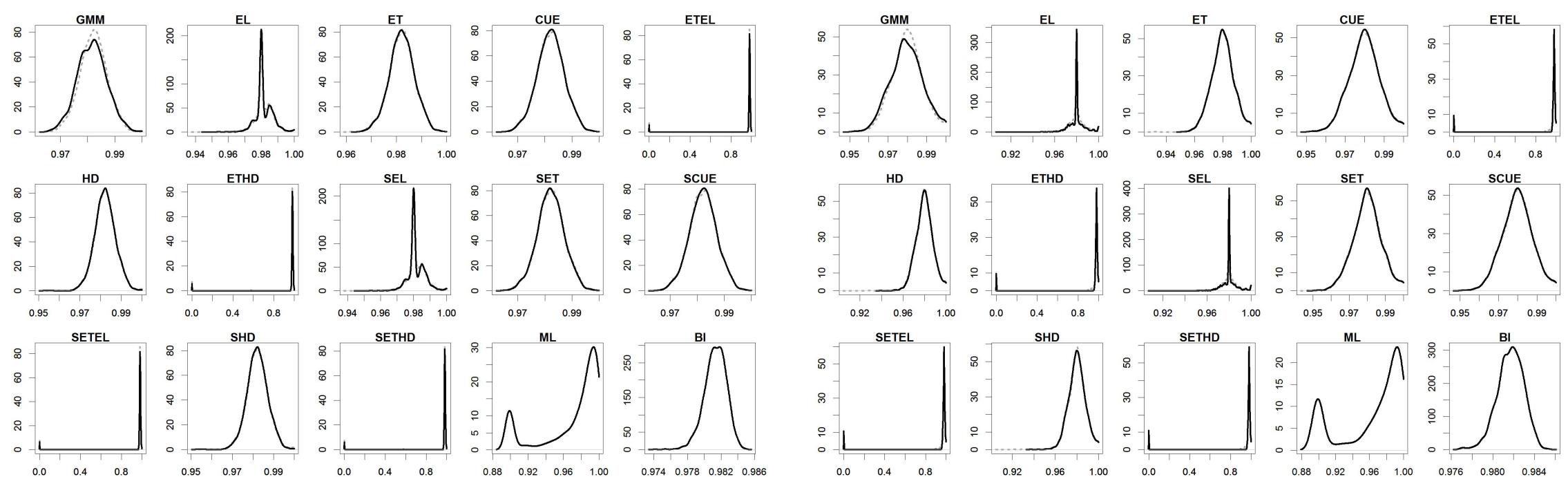

(c) DGP III: distribuição normal com outlier de posição fixa (centrado)

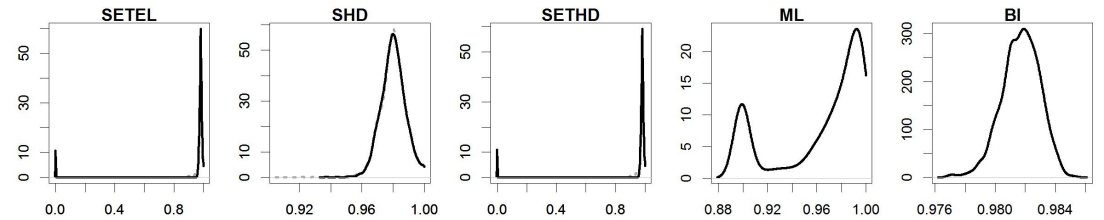

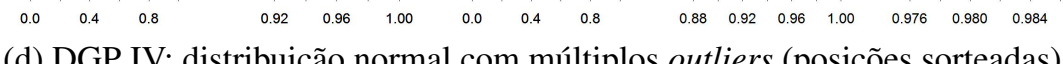

Notas: valor verdadeiro: $\beta=0,98$. Linha preta contínua: caso sobreidentificado. Linha cinza tracejada: caso exatamente identificado. 
Figura B.2 - Distribuição de $\hat{\gamma}$
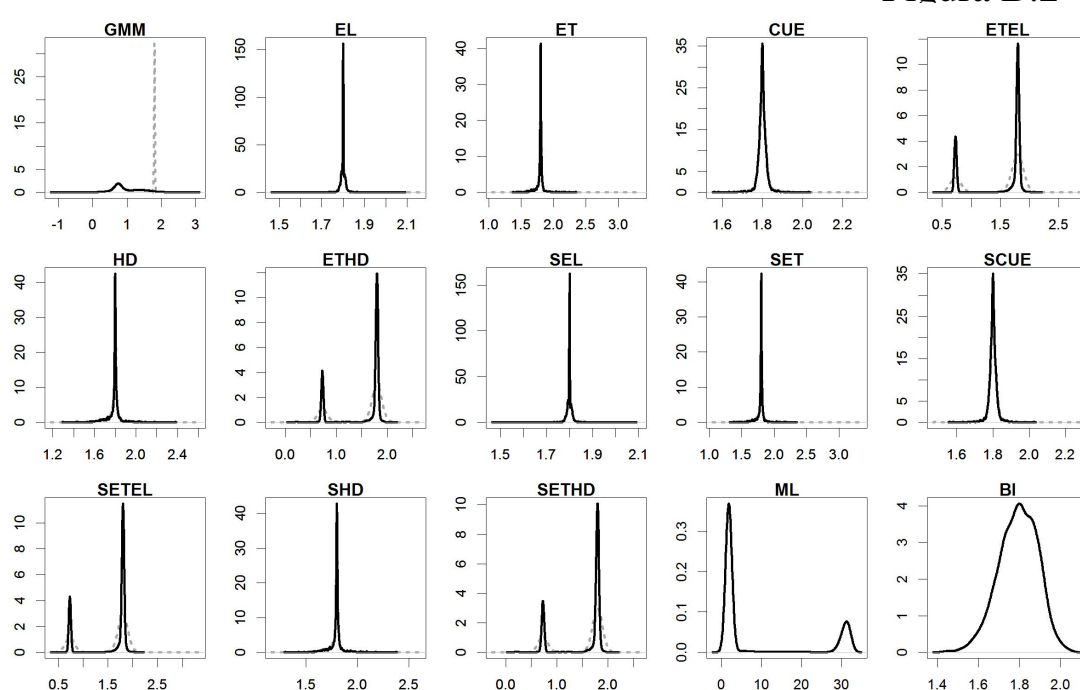

(a) DGP I: distribuição normal
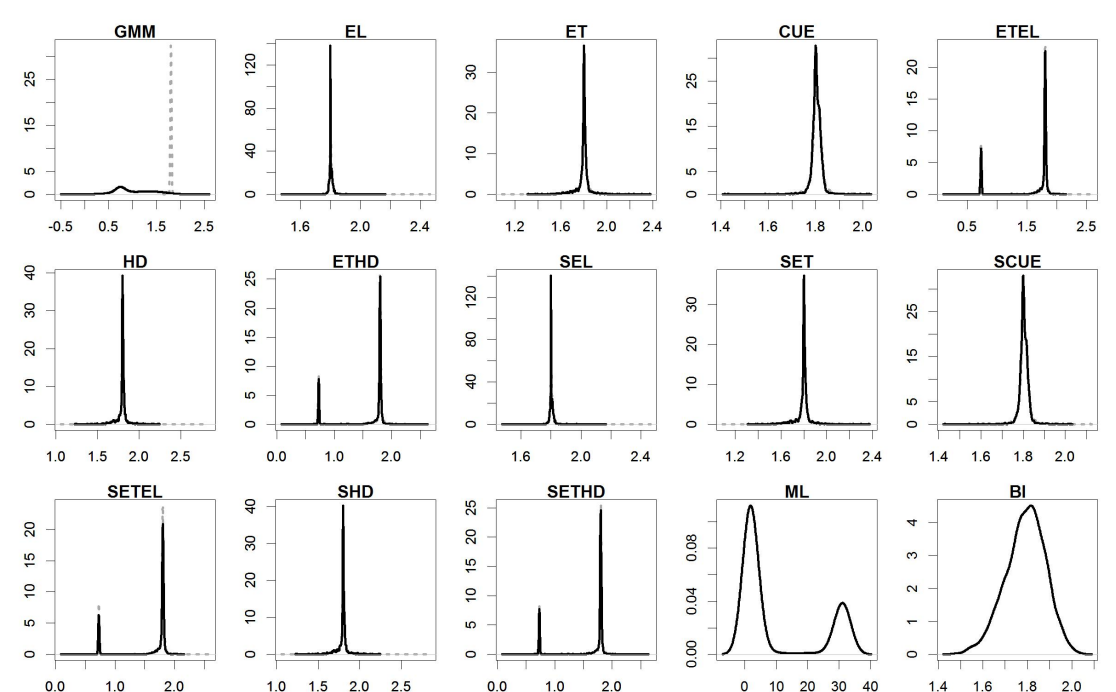

(c) DGP III: distribuição normal com outlier de posição fixa (centrado)
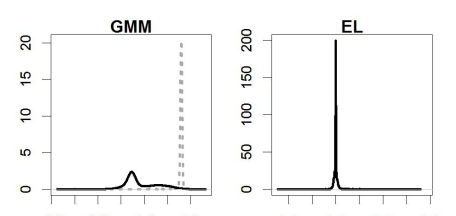

$\begin{array}{llllll}-1.0 & 0.0 & 1.0 & 2.0\end{array}$
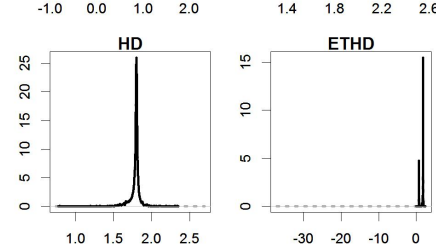

$\begin{array}{llll}-30 & -20 & -10 & 0\end{array}$
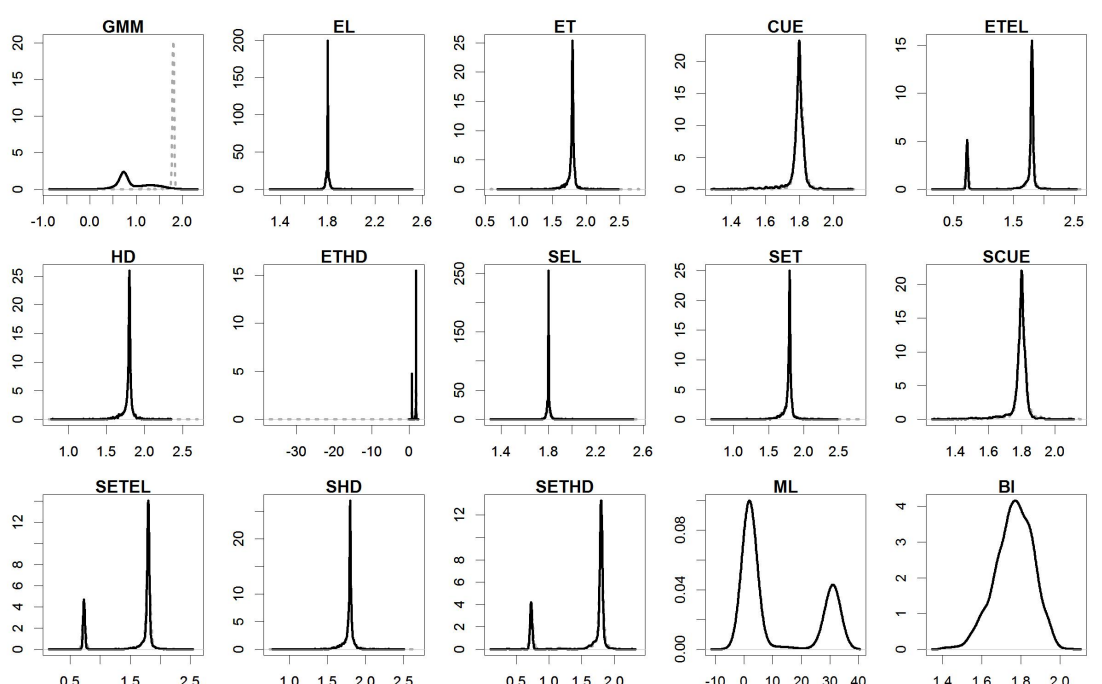

\begin{tabular}{llll}
0.5 & 1.5 & 2.5 \\
\hline
\end{tabular}
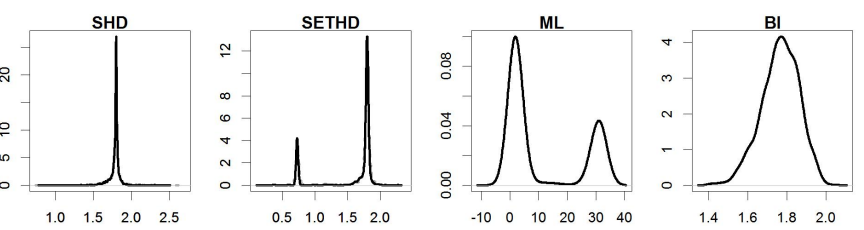

(b) DGP II: distribuição t
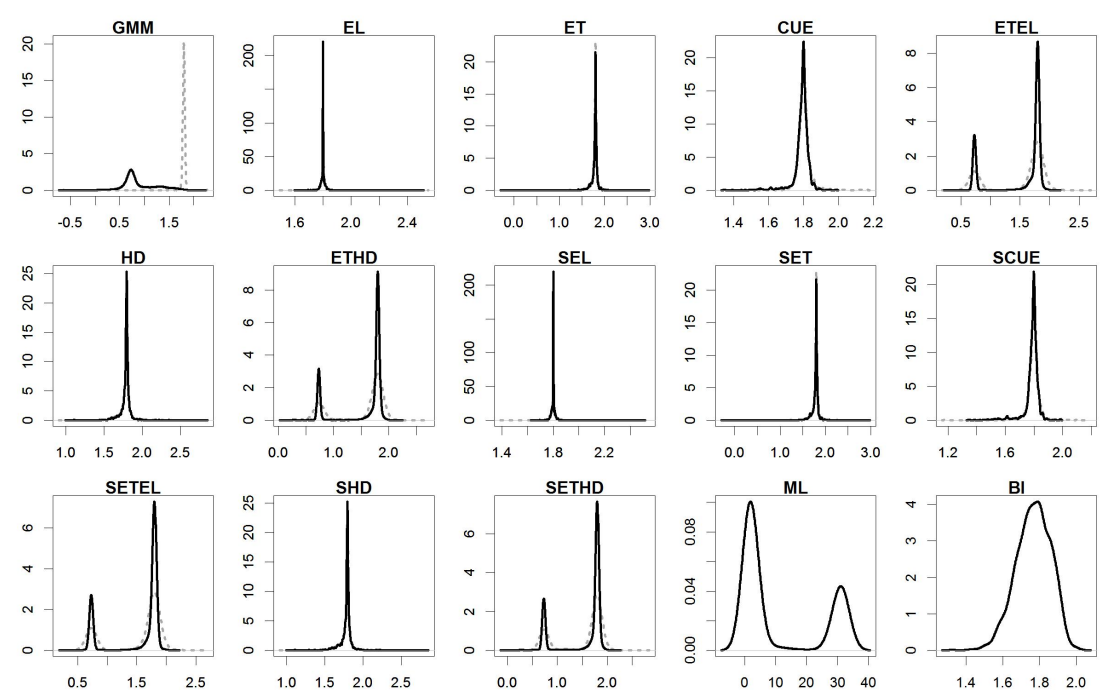

(d) DGP IV: distribuição normal com múltiplos outliers (posições sorteadas)

Notas: valor verdadeiro: $\gamma=1,8$. Linha preta contínua: caso sobreidentificado. Linha cinza tracejada: caso exatamente identificado. 


\section{Figura B.3 - Distribuição de $\hat{b}$}
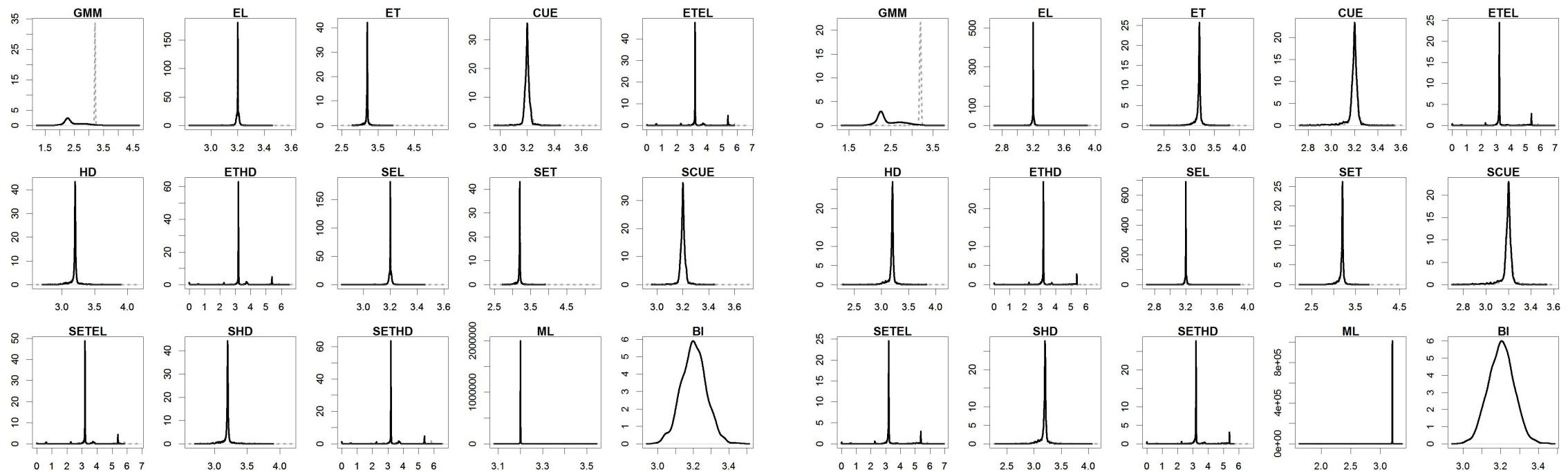

(a) DGP I: distribuição normal
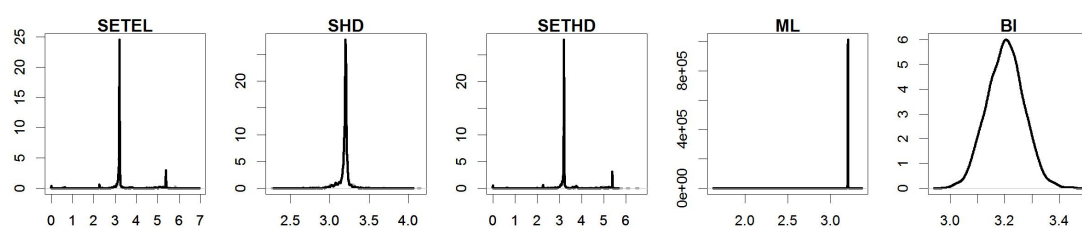

(b) DGP II: distribuição t
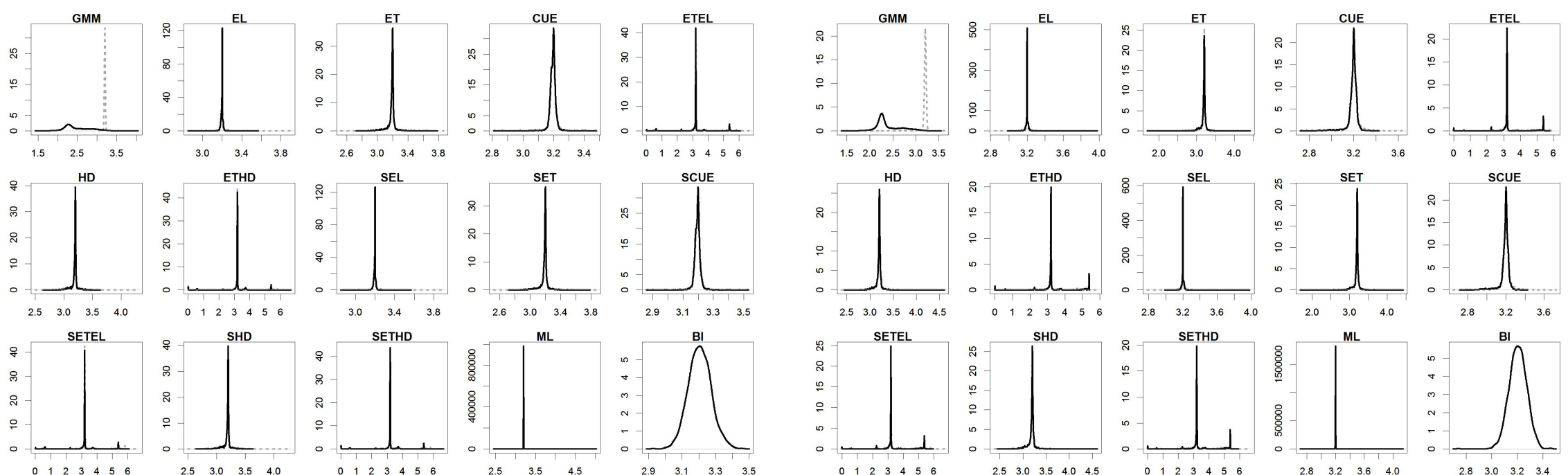

(c) DGP III: distribuição normal com outlier de posição fixa (centrado)
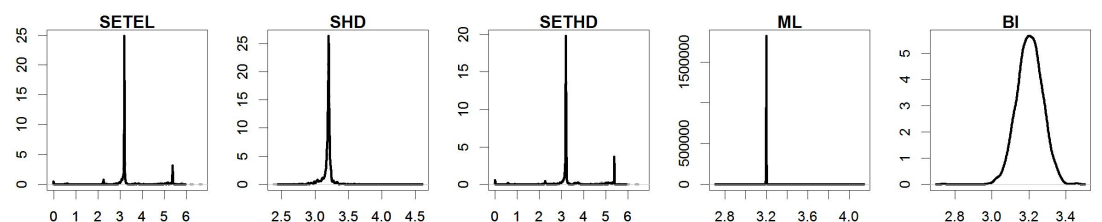

(d) DGP IV: distribuição normal com múltiplos outliers (posições sorteadas)

Notas: valor verdadeiro: $b=3,2$. Linha preta contínua: caso sobreidentificado. Linha cinza tracejada: caso exatamente identificado. 
Figura B.4 - Distribuição de $\hat{\rho}$
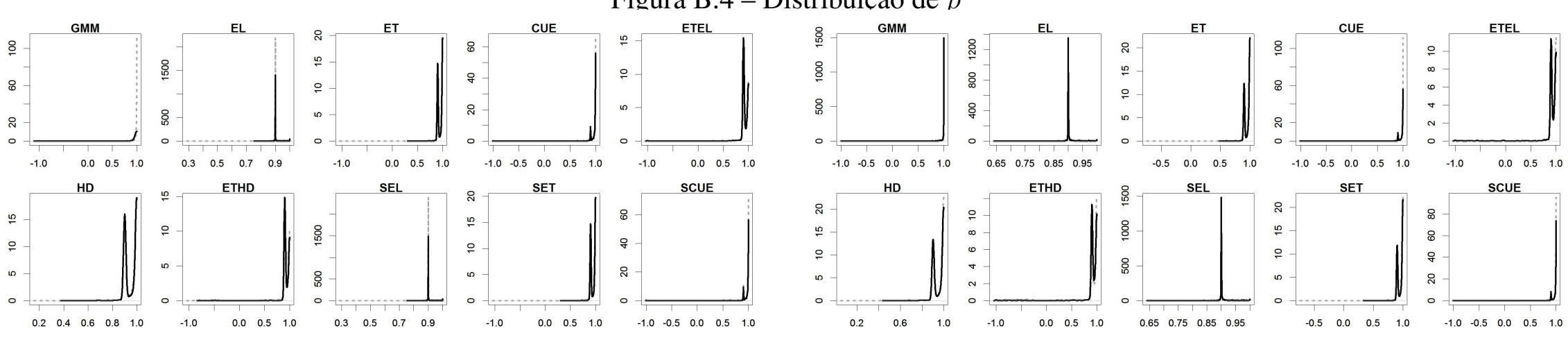

$\begin{array}{llll}-0.5 & 0.0 & 0.5 & 10\end{array}$

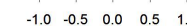

SCUE

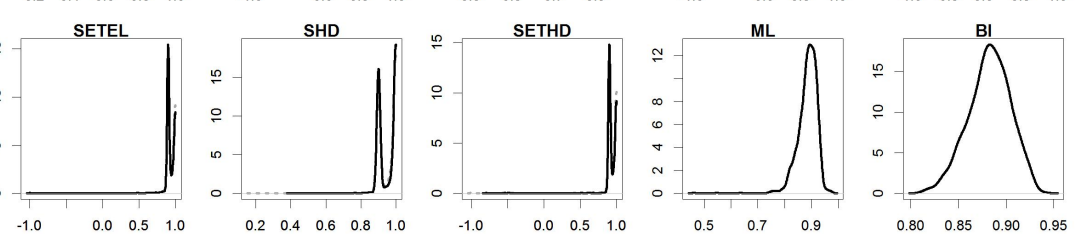

(a) DGP I: distribuição normal
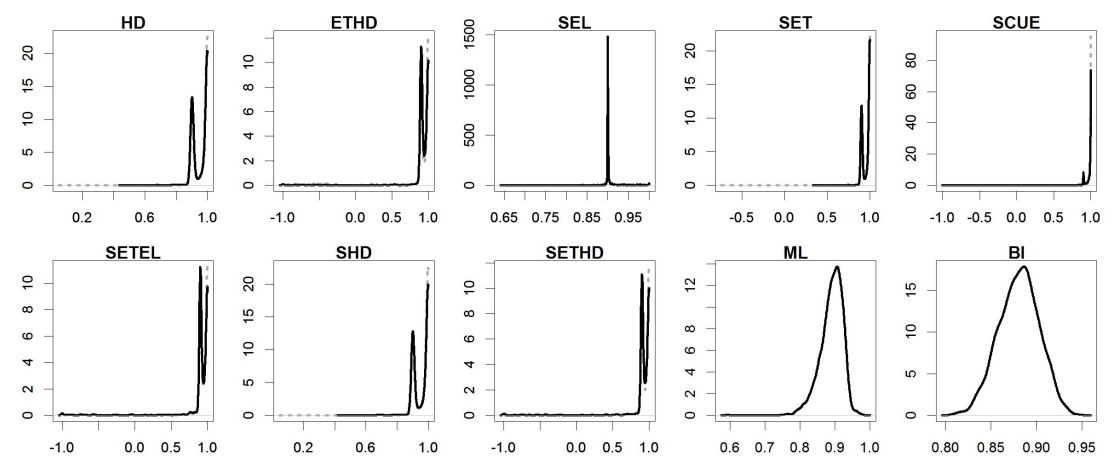

$\begin{array}{llllllllll}0.5 & 0.0 & 0.5 & 1.0 & -1.0 & 0.5 & 0.0 & 0.5 & 1.0\end{array}$

SETHD

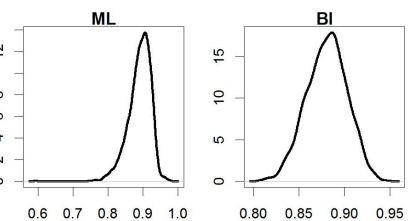

(b) DGP II: distribuição t
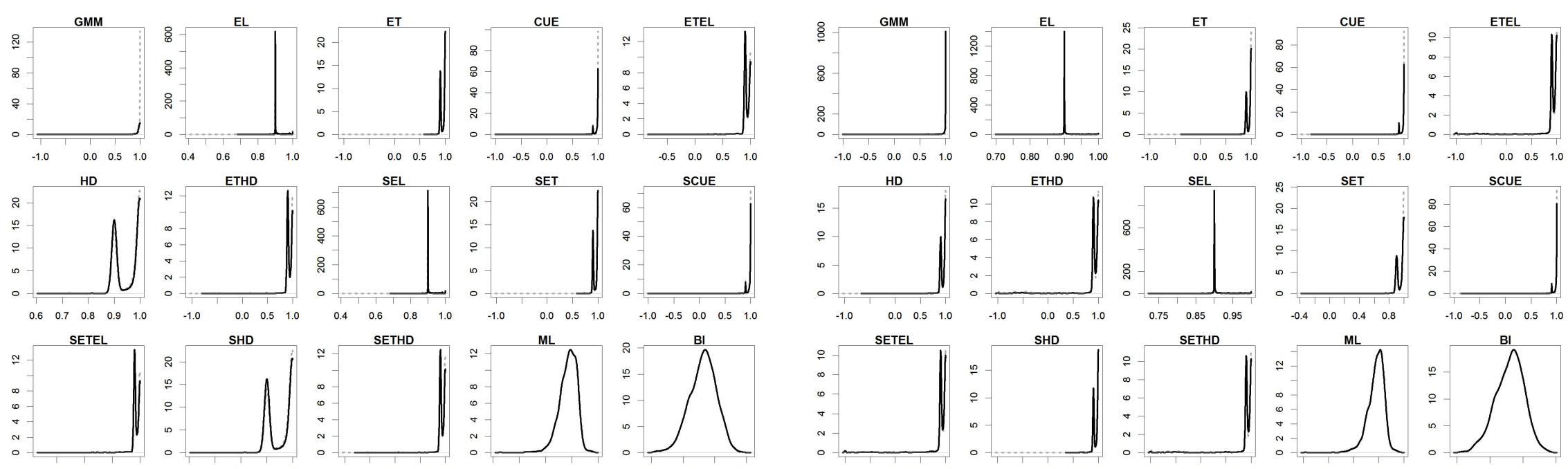

$\begin{array}{llllllllll}-1.0 & 0.5 & 0.0 & 0.5 & 1.0\end{array}$

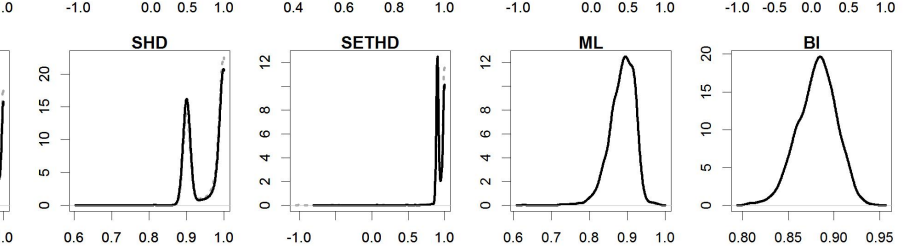

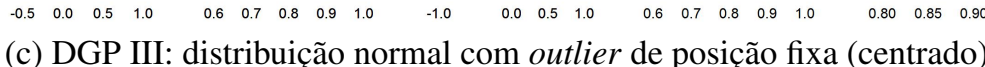

$0.5 \quad 10 \quad 000$
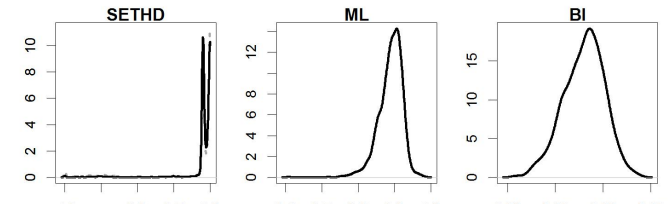

(d) DGP IV: distribuição normal com múltiplos outliers (posições sorteadas)

Notas: valor verdadeiro: $\rho=0,9$. Linha preta contínua: caso sobreidentificado. Linha cinza tracejada: caso exatamente identificado. 


\section{Figura B.5 - Distribuição de $\hat{\sigma}$}
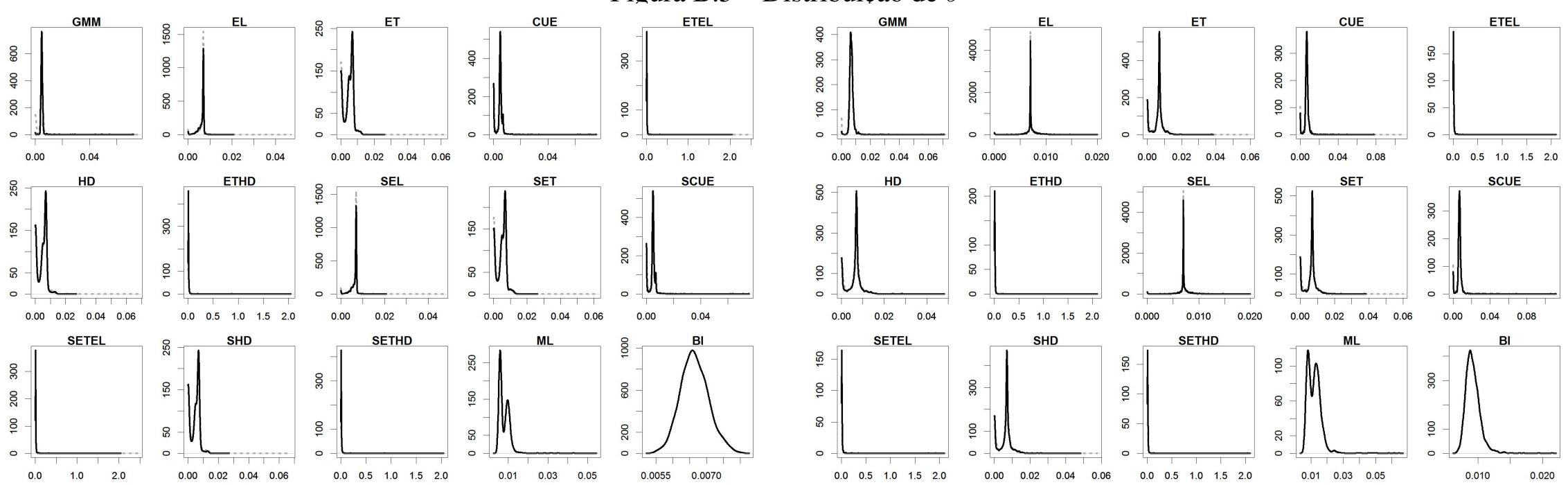

(a) DGP I: distribuição normal

(b) DGP II: distribuição t
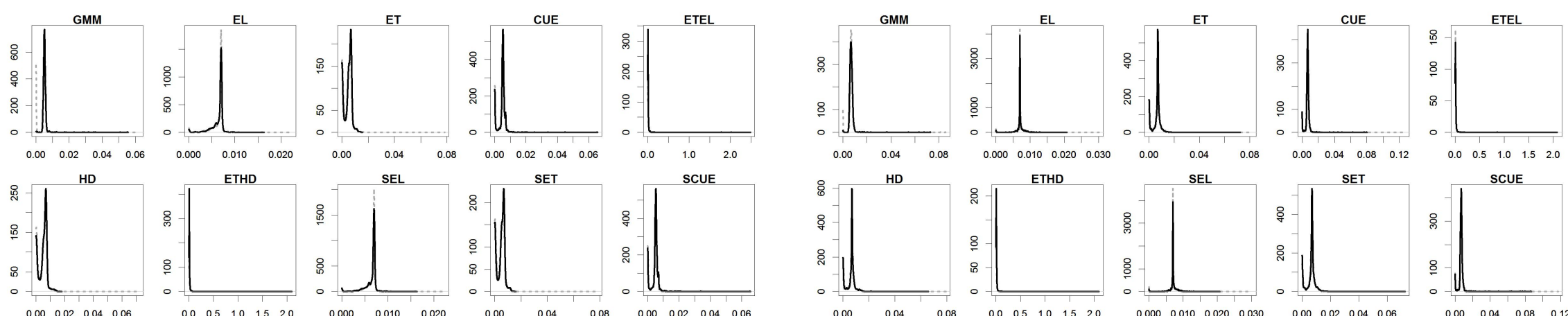

$\begin{array}{llll}0.00 & 0.04 & 0.08 & 0.12 \\ 0 & -10 & 0\end{array}$

$0.0 \quad 0.5 \quad 1.01 .5$
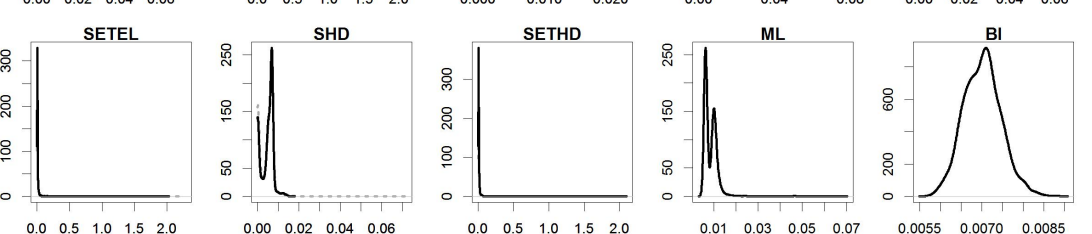

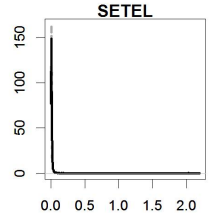
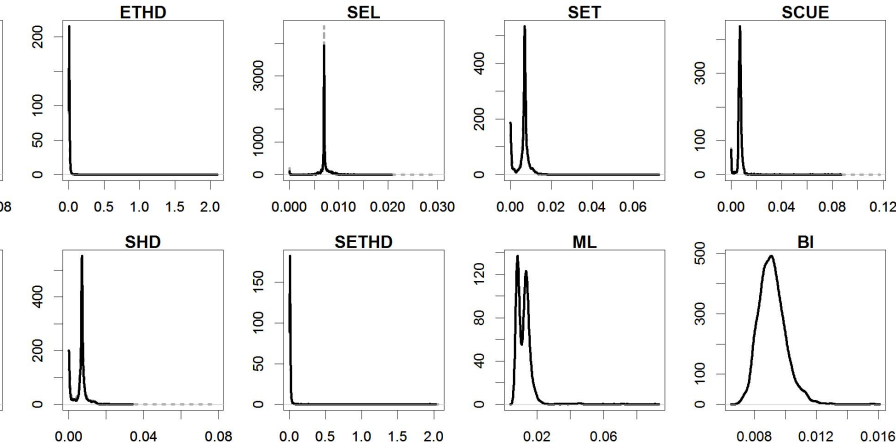

(c) DGP III: distribuição normal com outlier de posição fixa (centrado)

(d) DGP IV: distribuição normal com múltiplos outliers (posições sorteadas)

Notas: valor verdadeiro: $\sigma=0,007$. Linha preta contínua: caso sobreidentificado. Linha cinza tracejada: caso exatamente identificado. 